\title{
DESENVOLVIMENTO DE UM SENSOR DE PRECIPITAÇÃO E COLETOR DE DADOS VISANDO A AUTOMAÇÃO NO ENSAIO DE ASPERSORES.
}

\author{
Wilson Roberto Negri \\ Engenheiro Civil
}

Orientador: Prof. Dr. Tarlei Arriel Botrel

Dissertação apresentada à Escola Superior de Agricultura "Luiz de Queiroz", da Universidade de São Paulo, para obtenção do título de Mestre em Agronomia, Área de Concentração: Irrigação e Drenagem.

PIRACICABA

Estado de São Paulo - Brasil

Maio- 1995 


\section{CATALOGAÇÃONA PUBLICAÇÃO \\ DIVISÃO DE BIBLIOTECA E DOCUMENTAÇÃO - CAMPUS "LUIZ DE QUEIROZ"Y USP :}

Negri, Wilson Roberto

Desenvolvimento de um sensor de precipitação e coletor de dados visando a automação no ensaio de aspersores. Piracicaba, 1995.

$57 p$. ilus.

Diss.(Mestsre) - ESALQ

Bibliografia,

1. Aspersor - Ensaio - Automação 2. Irrigação por aspersão - Equipamento - Ensaio 3. Sensor automatizado - Desenvolvimento I. Escola Superior de Agricultura Luiz de Quieiroz, Piracicaba 


\section{DESENVOLVIMENTO DE UM SENSOR DE PRECIPITAÇÃO E COLETOR DE DADOS VISANDO A AUTOMAÇÃO NO ENSAIO DE ASPERSORES.}

WILSON ROBERTO NEGRI

Aprovada em: 10.08.1995

Comissão julgadora:

Prof. Dr. Tarlei Arfiel Botrel:

ESALQ / USP

Prof. Dr. José Antonio Frizzone

ESALQ / USP

Prof. Dr. Nilson Augusto Villa Nova

ESALQ / USP

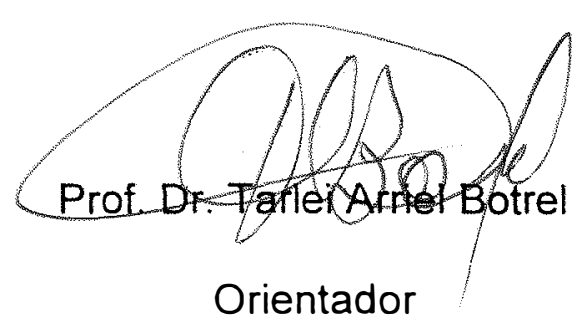


A minha mãe,

A meu pai (in memorian),

ofereço.

A minha esposa Arlete,

A minhas filhas: Patricia

e Mariana,

dedico. 


\section{AGRADECIMENTOS}

Ao Prof. Dr. Tarlei Arriel Botrel, Professor do Departamento de Engenharia Rural da ESALQ / USP, pela sugestão do assunto e valiosa orientação na elaboração deste trabalho.

A minha esposa Arlete pelos constantes estímulos, solidariedade e cooperação.

Às minhas filhas Patrícia e Mariana, pela atenção que Ihes foi suprimida.

Aos professores do Departamento de Engenharia Rural, pela receptividade e ensinamentos.

Ao Centro de Informática na Agricultura - CIAGRI, pela oportunidade oferecida na realização do curso.

Aos companheiros de trabalho, em especial ao Engenheiro Ricardo Ramiro, pelo apoio no desenvolvimento do conversor Analógico/Digital.

Ao colega Engenheiro Daniel Polleto, pelo empenho no desenvolvimento do equipamento de eletrônica analógica.

Aos colegas do Curso de Pós Graduação, pela amizade e companheirismo.

A todos que direta ou indiretamente colaboraram para a realização deste trabalho. 


\section{SUMÁRIO}

\section{PÁGINA}

1- INTRODUÇÃO

2-REVISÃO DA LITERATURA

2.1- Avaliação de aspersores.

2.2- Ensaios de campo.

2.3- Automação. 6

3- MATERIAIS E MÉTODOS.

3.1 - Descrição do método.

3.2 .1 - Fonte de Alimentação. 14

3.2.2 - Oscilador. 15

3.2.3 - Ponte de Wheatstone. 16

3.2.4 - Pré Amplificador/ retificador. 17

3.2 .5 - Amplificador. 17

3.2.6 - Conversor A/D. 17

3.2.7 - Placa Leitora/Controladora. 18

3.2.8 - Microcomputador. $\quad 18$

3.2.9 - Multiplexador. $\quad 19$

3.2.10 - Vasos Comunicantes. 19

3.3 - Softwares 19

4. CONSTRUÇÃO DO EQUIPAMENTO. 40

5. ENSAIOS. $\quad 45$

5.1 - Intervalo da coluna de água entre 361 e $760 \mathrm{~mm}$. 45

5.2 - Intervalo da coluna de água entre 178 e $695 \mathrm{~mm}$. 47

5.3 - Intervalo da coluna de água entre 161 e $733 \mathrm{~mm}$. 48

5.4 - Intervalo da coluna de água entre 161 e $695 \mathrm{~mm}$. 49

5.5 - Intervalo da coluna de água entre 190 e $712 \mathrm{~mm}$. 50

5.6 - Intervalo da coluna de água entre 390 e $643 \mathrm{~mm}$. 51

5.7 - Intervalo da coluna de água entre 288 e $760 \mathrm{~mm}$. 52

5.8 - Intervalo da coluna de água entre 202 e $602 \mathrm{~mm}$. 53 
6 - CONCLUSÃO.

54

REFERÊNCIAS BIBLIOGRÁFICAS. 


\title{
DESENVOLVIMENTO DE UM SENSOR DE PRECIPITAÇÃO E COLETOR DE DADOS VISANDO A AUTOMAÇÃO NO ENSAIO DE ASPERSORES.
}

\author{
Autor: Wilson Roberto Negri \\ Orientador: Prof. Dr. Tarlei Arriel Botrel
}

\section{RESUMO}

Com a finalidade de minimizar erros de leitura e anotação manual de dados de medição de campo, e agilização da coleta de dados para avaliação de aspersores, foi desenvolvido um sistema automático para aquisição de dados, que utiliza um sensor capacitivo eletrônico e uma placa conversora Analógica/Digital conectados a um microcomputador. O sensor foi implementado a partir de um conjunto mercúrio-vidro-cobre formando um capacitor cilindrico variável em função da pressão da coluna de água fornecidas por coletores construídos em forma de vasos comunicantes, conectado a uma ponte de Wheatstone alimentado por uma tensão de corrente alternada, fazendo com que o desbalaceamento da ponte gere uma tensão, que amplificada e retificada gera um sinal elétrico de corrente continua com 
variação entre 0 e 10 Volts. A tensão fornecida é enviada ao microcomputador onde é convertida em sinal digital através de um Circuito Integrado AD574A com valores entre 0 e 4095

O microcomputador, além de efetuar as leituras do conversor, controla um multiplexador para acionamento de solenóides para abertura e fechamento dos vasos coletores, e gera um arquivo com o registro das grandezas lidas.

Em ensaios realizados, os valores apresentados representaram erros inferiores a $1 \%$, o que se pode afirmar que o sistema é confiável. 


\title{
DESENVOLVIMENTO DE UM SENSOR DE PRECIPITAÇÃO E COLETOR DE DADOS VISANDO A AUTOMAÇÃO NO ENSAIO DE ASPERSORES.
}

\author{
Author: Wilson Roberto Negri \\ Adviser: Prof. Dr. Tarlei Arriel Botrel
}

\section{SUMMARY}

This Data Aquisition System of Evoluation Sprinkler was developed to avoid mistakes of measurement by reading an manual writing. The equipamnet wil become this work easier and faster. The system uses a sensor of capacitance and a A/D converter interface connected to a microcomputer slot.

The sensor of capacitance was built using a glass tube and cooper. The mercury inside of the tube moves according the water column pressure. The result is a cilinder capacitor where the mercury is a variable plaque, the glass tube is the dieletric, and the cooper completes the component. 
That capacitor is connected in a Wheatstone bridge powered with alternate current. The signal of the bridge is applied to an eletronic circuity to be amplified and retified. The find signal is a DC from 0 up to 10 Volts.

That voltage is driven to the computer interface based on a A/D Converter (I.C. AD574A), that gives 4096 digital values. The interface also has a multiplexer that can control valves switching the splinker under test.

Experiences with the system showed $1 \%$ accuracy. So the equipament is reliable. 


\section{1- INTRODUÇÃO}

Os testes de distribuição da precipitação de aspersores são necessários para caracterizar o desempenho dos mesmos, oferecendo aos usuários e projetistas de sistemas de irrigação, subsídios necessários para projetar criteriosamente sistemas de irrigação por aspersão.

Atualmente os testes de desempenho de aspersores são realizados pelas próprias empresas fabricantes e também por algumas universidades como a Universidade de São Paulo, através da Escola Superior de Agricultura "Luiz de Queiroz", pioneira nestes tipos de testes, sendo realizados desde a década de 60 . A metodologia de ensaio utilizada pelos citados órgãos, consiste basicamente em distribuir pluviômetros em torno do aspersor a ser avaliado, e fazê-lo funcionar por algum tempo (geralmente 1 hora), e após este funcionamento procede-se a leitura dos pluviômetros por processo manual. A NBR 8988 da Associação Brasileira de Normas Técnicas ABNT, estabelece como limite minimo o número de 50 pluviômetros a utilizar em cada ensaio, porém na prática este número geralmente ultrapassa 80 . A 
leitura, anotação e digitação destes dados, é um trabalho repetitivo e sujeito a erros de coleta do operador, ou mesmo do digitador.

Considerando ainda que um único aspersor pode trabalhar com 12 jogos de bocais diferentes e a 5 niveis de pressão, gerando necessidade de uma avaliação para cada combinação bocal-pressão, o trabalho para avaliação de aspersores se torna laborioso.

A introdução de sensores computadorizados permitirá aos pesquisadores uma rápida e confiável avaliação dos resultados obtidos em campo, com a certeza de isenção de erros gerados entre as medições no campo até a digitação dos dados para obtenção dos resultados finais.

Com o avanço do setor de eletrônica e a facilidade de se encontrar componentes eletrônicos no mercado, torna-se fácil a automação desses trabalhos.

Este trabalho se propõe a desenvolver um sensor de precipitação automatizado para leitura e transferência das leituras para um microcomputador por meio de um software.

O projeto inclui a construção de um medidor de baixa variação de lâmina d'água através de um conjunto vidro-mercúrio simulando um capacitor variável, conversão da variação da capacitância em variação de tensão elétrica alternada, construção de retificador de corrente alternada em corrente 
contínua, construção de um amplificador de sinal em tensão ajustável de 0 a 10 volts que alimentando um conversor analógico-digital fornece valores de 0 a 4095, lidos por um microcomputador, onde se encontra um sistema gerador de arquivos em valores convertidos para colunas d'água.

O módulo de conversão AVD é composto ainda de um sistema de acionamento de duas saídas de sinais de 24 linhas cada, podendo controlar até 576 válvulas solenóides de abertura e fechamento dos coletores para medição individual.

O sistema de conversão de variação de coluna de mercúrio em dados digitais está construido em um módulo integrado, que é conectado a um microcomputador onde será instalada uma interface para leitura desses valores, e um conjunto de saidas que controlarão os solenóides existentes em cada coletor onde estão as lâmina d'água a serem medidas.

Este projeto foi baseado no experimento montado por FISHER \& WALLENDER (1988), visando a completa automação do sistema, com a construção do sensor de precipitação e do conversor Analógico Digital a baixo custo. 


\section{2-REVISÃO DA LITERATURA}

2.1- Avaliação de aspersores.

As recomendações de aspersão, geralmente são realizadas com base na análise da uniformidade de distribuição, dentro de padrões de distribuição de água sobrepostos. Tais padrões são então comparados com outros, através de coeficientes calculados por meio dos dados de precipitação dos coletores.

Segundo CHRISTIANSEN (1942), os aspersores distribuem água em áreas circulares, não sendo possível obter uma aplicação com absoluta uniformidade. O grau de uniformidade vai depender do tipo de distribuição, que é função do vento, pressão de serviço, uniformidade de rotação dos aspersores, altura das hastes, diâmetro e tipo de bocal. A uniformidade depende também do espaçamento entre aspersores.

SATTO (1978) baseando-se num programa de computador para superposição de precipitações a partir de um aspersor desenvolvido por HART (1963), estudou a relação entre diversos coeficientes de uniformidade. 


\section{2- Ensaios de campo.}

SOLOMON (1984) conduziu estudos para analisar a variabilidade dos testes de uniformidade de aspersores. Segundo o autor, os resultados são alterados por medições imprecisas dos volumes de água coletados, da velocidade e direção dos ventos e da pressão; além das diferenças físicas de aspersores de um mesmo modelo ( bocais, mecanismos de rotação, etc.). $\mathrm{O}$ autor afirma que pequenas diferenças de fabricação, podem afetar significativamente as caracteristicas do jato que deixa o aspersor, atuando na distribuição de água e nos coeficientes de uniformidade.

COELHO et al (1992) afirmam que a disposição retangular de coletores, prevista na norma da ABNT para ensaio de aspersores, leva a uma trabalhosa e cansativa mensuração de volumes coletados, dificultando bastante a realização de ensaios. Os autores realizaram estudos visando comparar os tipos de ensaio, com coletores em disposição retangular e radial, analisando valores de CUC dos testes. Concluiram que existe elevada correlação entre os resultados obtidos através das duas metodologias, o que credencia os ensaios radiais para testes em laboratório, pela facilidade de instalação e operacionalização, economicidade e possibilidade de extrapolar resultados. 


\section{3- Automação.}

DODI (1990), construiu um sistema coletor automático para ensaio de microaspersores, utilizando transdutores em substituição aos coletores adicionais. Estes transdutores, quando alimentados por um circuito oscilador, geram um sinal elétrico proporcional à grandeza medida (nível líquido). O sinal fornecido a um sistema de aquisição de dados a partir do interfaceamento A/D possibilita a avaliação do perfil de distribuição bem como a uniformidade de distribuição de água aplicada por um microaspersor. A calibração desse sistema é bem abrangente, permitindo tanto o seu uso na avaliação da uniformidade de distribuição em sistemas de irrigação como em qualquer outro sistema que necessite da leitura da lâmina d'água.

Em 1987, o Ministério da Indústria e Comércio em conjunto com o STI, financiaram um projeto desenvolvido pelo Departamento de Engenharia Rural e pelo Centro de Informática na Agricultura, da USP em Piracicaba, desenvolvendo um microcomputador dedicado para aquisiçăo de dados em campo para máquinas agrícolas, cuja discussão foi publicada na revista MAQUINARIA AGRICOLA (1991).

FISCHER \& WALLENDER (1988), construiram um sistema para análise do tamanho do coletor e duração dos testes, em medidas de distribuição de água por aspersores, construindo para isso um sistema 
composto de um condutor horizontal suportando vários coletores, e uma das extremidades conectada a um transdutor de pressão ligado a um sistema de coletor de dados. Em cada base dos coletores foi instalado uma válvula solenóide para abertura individual, fazendo consequentemente a leitura de cada coletor.

Seguindo os exemplos de SPIESS(1983) e FISCHER \& WALLENDER (1988), SEGINER et Al (1992) construiram um sistema composto de tanque de água e bomba de pressão, alimentado continuamente um aspersor, cuja precipitação era recolhida em um conjunto receptores interligados a um transdutor de pressão, cujas leituras e acionamentos das válvulas solenóides eram controladas por um computador, o que permitia uma análise contínua da precipitação.

THONY \& GEORGES (1979) procederam a leitura automática de pressão de água no solo, construindo um manômetro capacitivo, que consistia em um tensiômetro formado por um tubo de vidro revestido com óxido de índio (condutor de eletricidade) formando uma das placas do capacitor e o elemento dielétrico, a outra placa do capacitor era formada pelo mercúrio de altura variável conforme a pressão da água no solo. A capacitância era transformada em tensão através de um Circuito Integrado LM 2097 N8 (conversor de freqüência em tensão), e lido através de um sistema conversor Analógico/Digital 


\section{3- MATERIAIS E MÉTODOS.}

3.1 - Descrição do método.

O sistema completo é composto por um conjunto de coletores de dados de precipitação, medição e transferências, baseados em três módulos físicos, conforme mostra a Figura 1, um módulo de software para controle do sistema de medição.

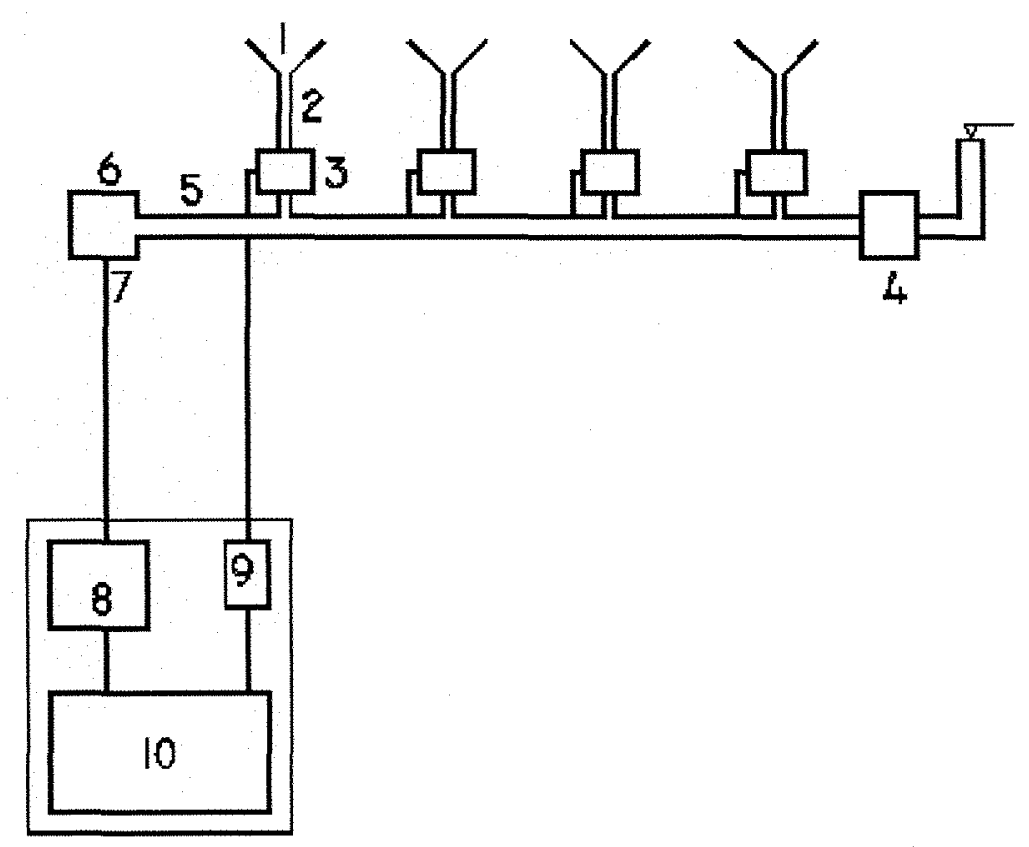

FIGURA 1 - Esquema geral do Medidor de Precipitação 
A precipitação do aspersor cairá sobre os funis coletores (1), ocupando diferentes alturas na haste de subida (2), sendo esta altura proporcional à precipitação coletada pelos funis. Para obter a leitura da precipitação, o microcomputador (10) comandará sequencialmente através do multiplexador (9), a abertura de válvulas solenóides, uma por vez, e fará a respectiva leitura da pressão através da capacitância produzida pela variação da altura da coluna de mercúrio ( Figura 2 ). Essa pressão corresponde à altura da água no tubo de subida (2), sendo, por sua vez, proporcional à precipitação captada pelo funil. A válvula de drenagem (4) será acionada juntamente com as válvulas solenóides, no inicio da operação, para drenar a água coletada em todos os funis, e preparar o sistema para teste, deixando todos os coletores inicialmente com o mesmo nivel de água.

O comando das operações de abertura das válvulas solenóides, e a leitura da pressão do mercúrio será feita pelo microcomputador, por intermédio da placa controladora e acionará os relês dos solenóides, efetuando a leitura e armazenamento dos dados obtidos, para posterior processamento dos mesmos. 


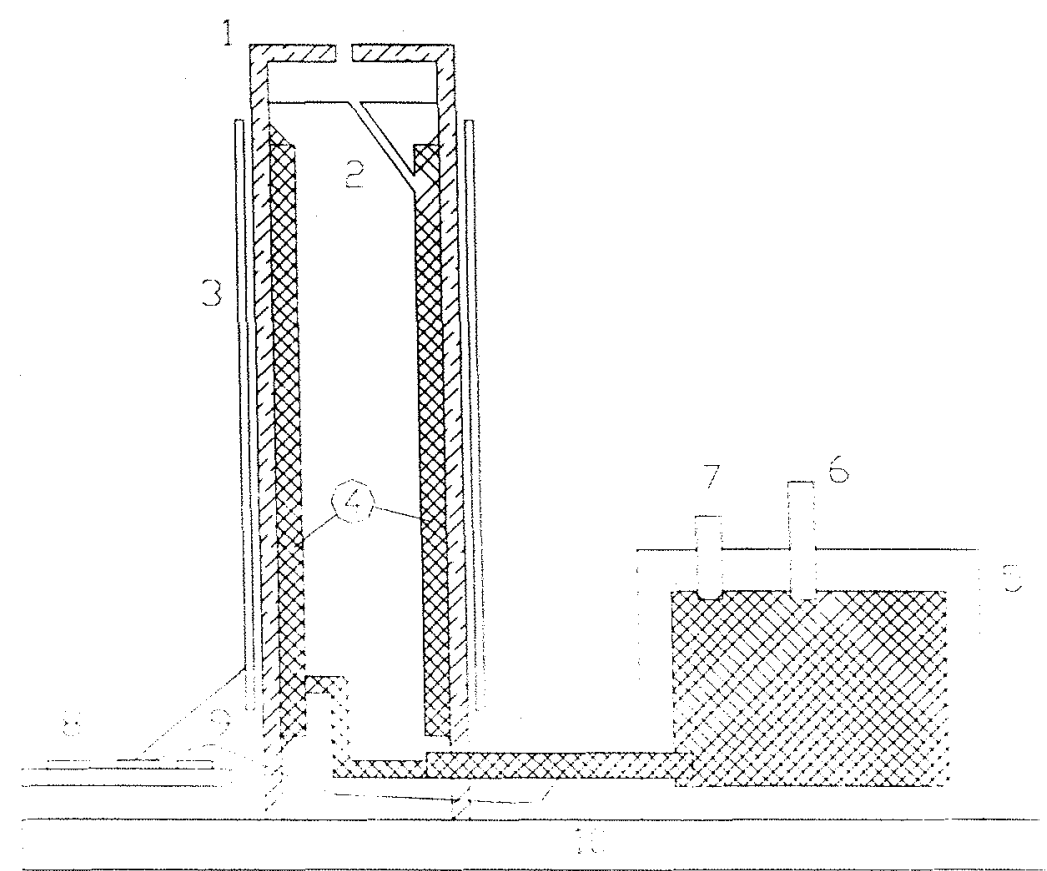

FIGURA 2 -Capacitor variável de coluna de mercúrio.

A Figura 2 mostra o medidor de pressão, constituido de um tubo de vidro (1) contendo mercúrio, que terá seu nivel definido pela pressão provocada pela coluna d'água existente na haste de subida (6). Internamente ao tubo de vidro se encontra um cilindro de PVC (2) com orificios para interligação do mercúrio, funcionando basicamente como redutor do volume de mercúrio. Envolto ao tubo de vidro é colocado uma lâmina de cobre (3) funcionando como uma das paredes do capacitor. O mercúrio interno ao tubo atua como a outra parede do capacitor, usando como dielétrico o tubo de vidro. Ao lado do tubo de vidro (1) encontra-se interligado um recipiente de diâmetro bem maior ao do tubo (5) provocando pouca variação na altura do mercúrio, quando submetido à pressão da água proveniente da haste de subida pelo 
orificio de entrada de água (6). Anexo ao conjunto, está o circuito conversor de capacitância em tensão.

A placa controladora, a ser instalada em um slot do microcomputador é composta de um decodificador de endereços acionado por meio de um software, um conjunto de circuitos integrados fazendo a leitura dos valores recebidos do conversor $A / D$, e também enviando dados para um integrado (PPI) de saída de 24 bits, que atuando num multiplexador composto de uma matriz $20 \times 24$, aciona os relês de comando das válvulas solenóides.

As Figuras 3 e 4 se referem ao projeto eletrônico do módulo do sensor e amplificador. 


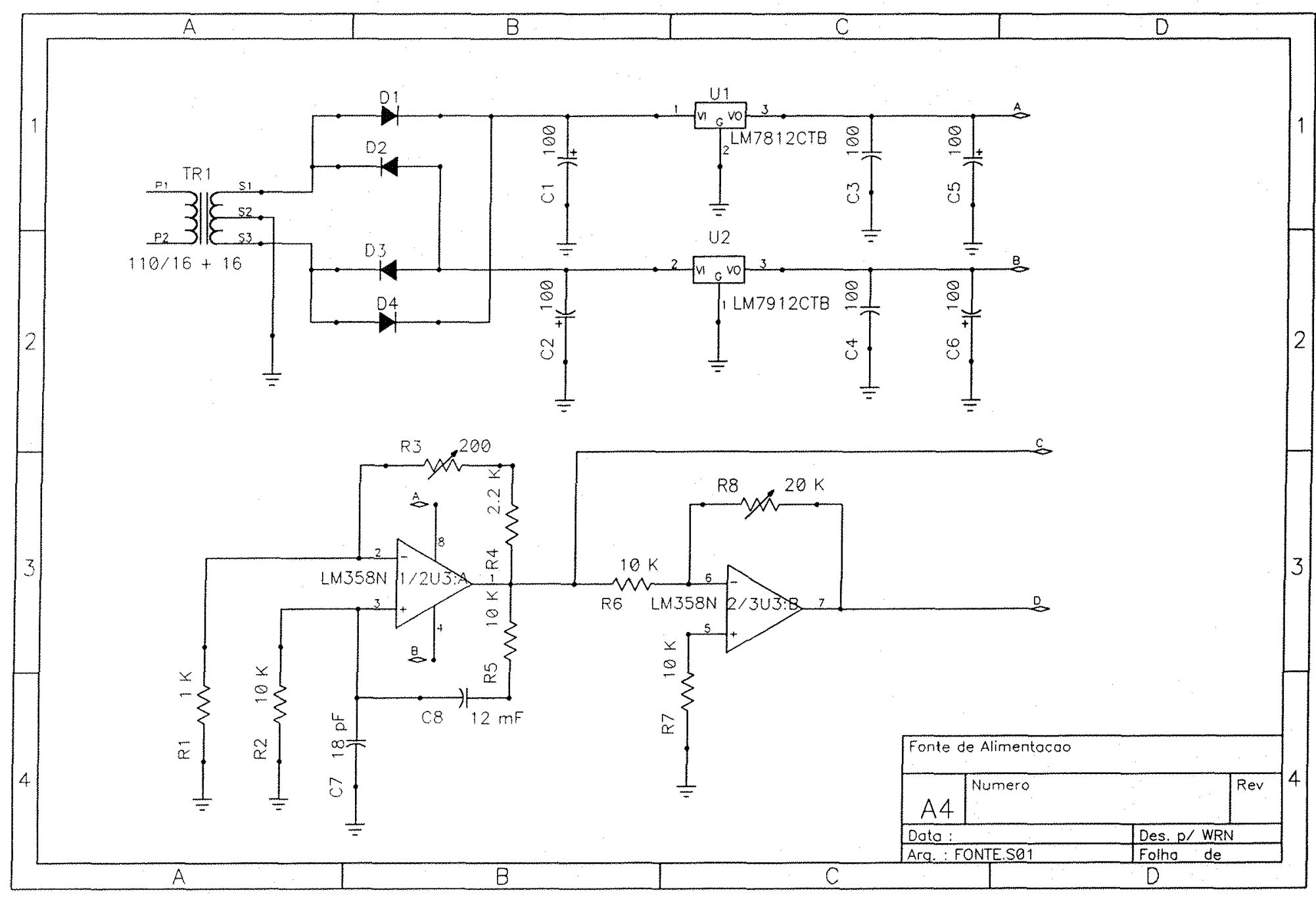

FIGURA 3 - Esquema Elétrico da Fonte de Alimentação e oscilador. 


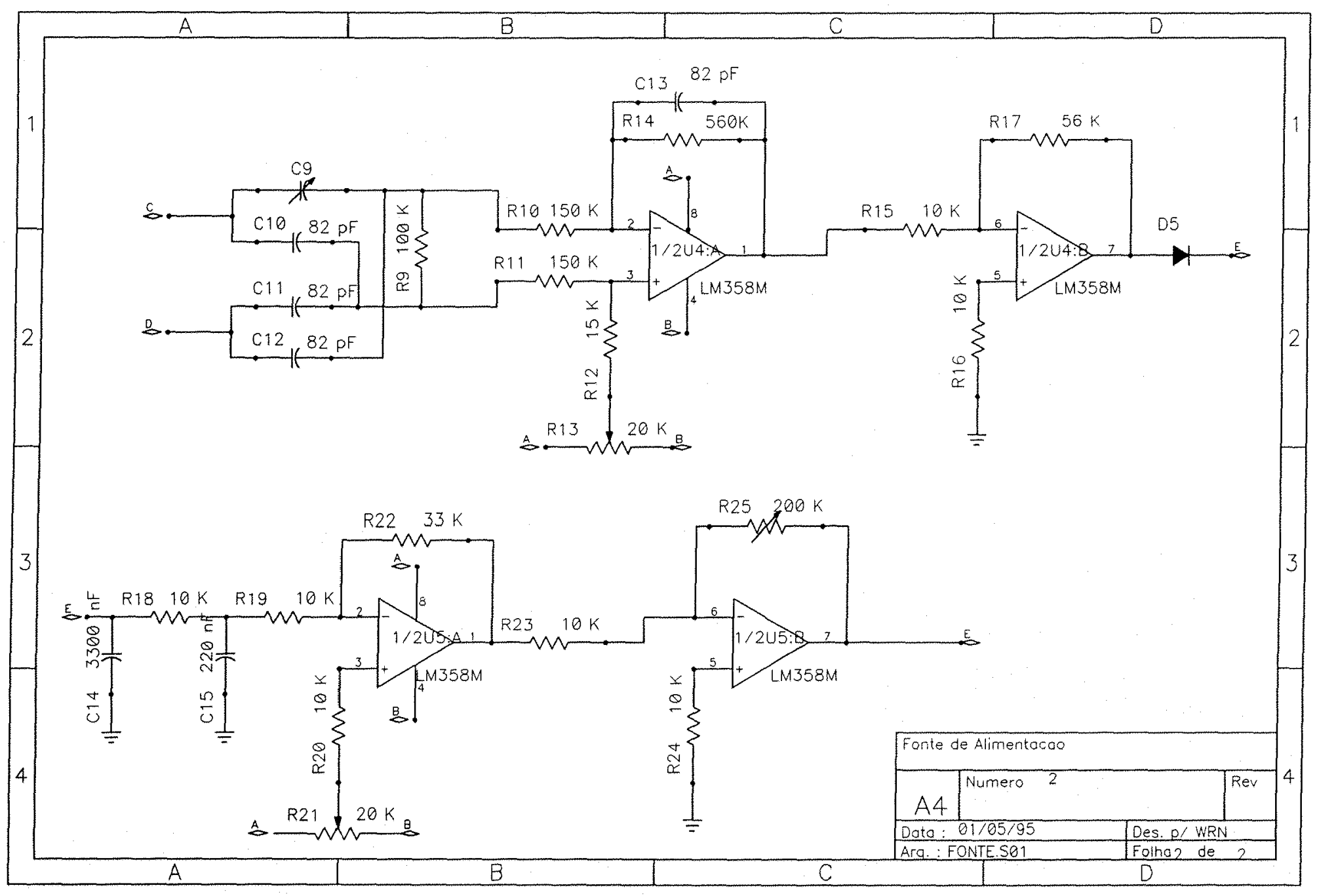

FIGURA 4 - Esquema Elétrico do Retificador e Amplificador. 
3.2 - Descrição dos módulos

O diagrama abaixo representa os módulos construídos para o sistema.

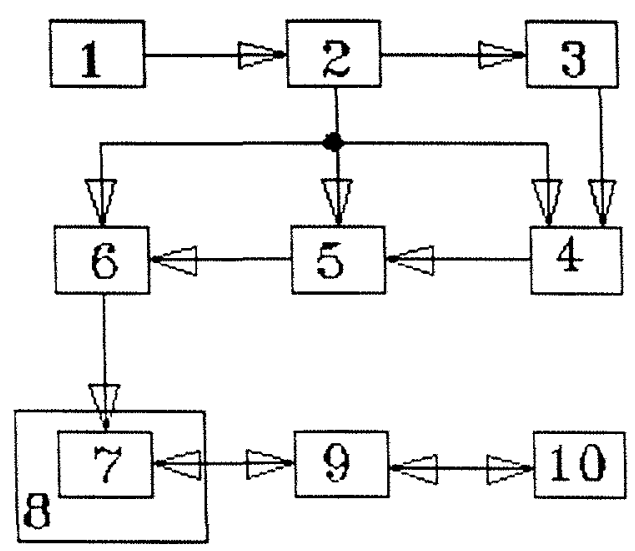

FIGURA 5. - Diagrama de blocos do Sistema

\subsection{1 - Fonte de Alimentação.}

A alimentação do circuito é feita pela rede elétrica comercial, com tensão de 110 Volts, $60 \mathrm{~Hz}$, num transformador que reduz a tensão para 16 Volts $60 \mathrm{~Hz}$. Essa tensão é retificada, e através dos integrados LM358N, é reduzida para tensões de +12 e -12 Volts para alimentação de todo o circuito. A partir da tensão retificada foi construído um oscilador com um circuito integrado LM358N, gerando uma frequência alternada senoidal de $600 \mathrm{~Hz}$ e 12 Volts de tensão de pico. 
A corrente alternada alimenta uma ponte de Weathestone, onde um dos elementos é o capacitor variável formado pelo conjunto mercúrio, vidro e lâmina de cobre. A tensão produzida pelo desbalanceamento da ponte é ampliada 20 vezes através de amplificadores operacionais $L M 358 \mathrm{M}$ e retificada em meia onda por meio de um diodo. Após a retificação, o sinal passa por um filtro Pi para eliminar os sinais indutivos de $60 \mathrm{~Hz}$, alimentando finalmente um amplificador, também construido com circuitos integrados LM358M, com ajustes de zero e de amplitude, podendo qualquer variação de coluna de mercúrio ser ajustada para tensões entre 0 a 10 Volts.

\section{2 .2 - Oscilador.}

Para a alimentação da ponte de Wheatstone formada por capacitores, deve-se usar corrente alternada senoidal. Para eliminar possiveis variações de tensão da rede elétrica, foi construido um oscilador de $600 \mathrm{~Hz}$, e tensão de pico de 12 Volts, a partir da fonte de alimentação, onde a tensão é estável. 


\subsection{3 - Ponte de Wheatstone.}

A ponte de Wheatstone foi construida com 3 capacitores de $82 \mathrm{pF}$ e o capacitor formado pelo conjunto cobre,vidro e mercúrio. $O$ valor de $82 \mathrm{pF}$ foi determinado pelo menor valor da capacitância fornecida pelo capacitor variável.

O capacitor variável é constituido por dois cilindros condutores coaxais separados por pequena distância a fim de que a indução seja praticamente total. O cilindro interno pode ser oco ou maciço.

A construção do capacitor foi implementada a partir de um tubo de vidro, usado como dielétrico, de $1,5 \mathrm{~mm}$ de parede e diâmetro interno de 25 mm. Internamente ao tubo de vidro é colocado um cilindro de PVC com diâmetro inferior ao diâmetro interno do tubo de vidro para reduzir o volume de mercúrio.

O valor da capacitância é dado por :

$$
C=\frac{2 \cdot \pi \cdot \varepsilon_{r} \cdot \varepsilon_{0} \cdot L}{\ln \left(\frac{R_{2}}{R_{1}}\right)}
$$

onde:

C - Capacitância, Farad;

$\varepsilon_{\mathrm{r}}$ - Constante relativa, (para o vidro vale de 1,6 a 5) adimensional;

$\varepsilon_{0}$ - Constante dielétrica. Vale 8,86 $10^{-12} \mathrm{As} / \mathrm{Vm}$;

$\mathrm{L}$ - Altura do cilindro, $\mathrm{m}$; 
$R_{1}$ - Diâmetro interno do cilindro, $m$;

$R_{2}$ - Diâmetro externo do cilindro, $m$

Substituindo os valores na equação, teremos o valor da capacitância entre 1,53 a 4,77 pFarad por milimetro de mercúrio.

3.2.4 - Pré Amplificador/ retificador.

Como a tensão fornecida pelo desbalanceamento da ponte é muito baixa, foi necessário amplificar essa tensão antes de sua retificação.

3.2.5 - Amplificador.

Esse amplificador foi instalado no circuito, para produzir uma tensão de saída entre 0 e 10 Volts, sendo ajustável a tensão de 0 Volt para a menor coluna de mercúrio, e 10 Volts para a máxima coluna de mercúrio, tornando-se assim, o sensor, adaptável para grande faixa de medições.

\subsection{6 - Conversor A/D.}

As tensões fornecidas pelo amplificador alimentam um conversor Analógico/Digital, com saída de 12 bits, fornecendo-se assim uma variação de 
4095 unidades de leituras para uma variação de 10 Volts, sendo que cada unidade lida corresponde a 0,0024 Volts.

\subsection{7 - Placa Leitora/Controladora.}

Esta placa, inserida em um "slot" do microcomputador e controlado pelo "software" desenvolvido se encarrega de fazer a leitura do conversor A/D e acionar as saídas do multiplexador.

Esse circuito consiste da combinação de vários integrados do tipo $T T L$, com portas lógicas, que combinam os valores dos bits recebidos do barramento do microcomputador, ativando as entradas e saidas do conversor $A / D$, fazendo com que o valor convertido seja armazenado no buffer e transferido para o software sendo executado.

Outra função deste circuito é também controlar duas PPIs (peripherical programable interface), de onde são emitidos os sinais de 24 bits cada uma delas, que associados de 2 em 2 podem controlar até 576 relês para acionamento dos solenóides.

\subsection{8 - Microcomputador.}

Pode ser um microcomputador da linha IBM PC ou AT, com configuração mínima, tendo livre pelo menos um "slot" de 8 bits. 


\subsection{9 - Multiplexador.}

Esse multiplexador é um circuito acionado pela saída dos pinos da PPI, onde através de uma malha de $24 \times 24$ aciona simultaneamente ou individualmente os solenóides de abertura dos coletores. Esse multiplexador pode controlar até 576 solenóides.

\subsubsection{0 - Vasos Comunicantes.}

É o conjunto de vasos comunicantes constantes de coletores a serem medidos, acionados por solenóides. Este conjunto está representado na Figura 1.

\section{3 - Softwares}

Foi desenvolvido um software na linguagem Turbo Pascal, com rotinas em baixo nivel, para controle do sistema, ou seja: acionamento da portas de saida para acionamento dos solenóides, controle e leitura dos dados convertido pelo $A / D$, calibração do conjunto, e geração de um arquivo texto com os dados lidos no conversor, cuja listagem vem a seguir:

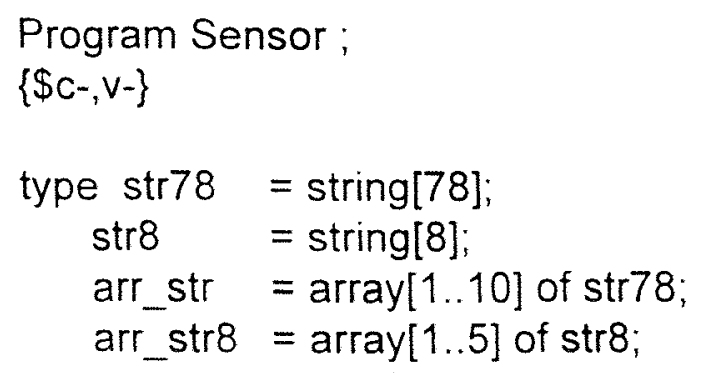


arr_real $=$ array $[1 . .20]$ of real;

arr_int $=\operatorname{array}[1 . .20]$ of integer;

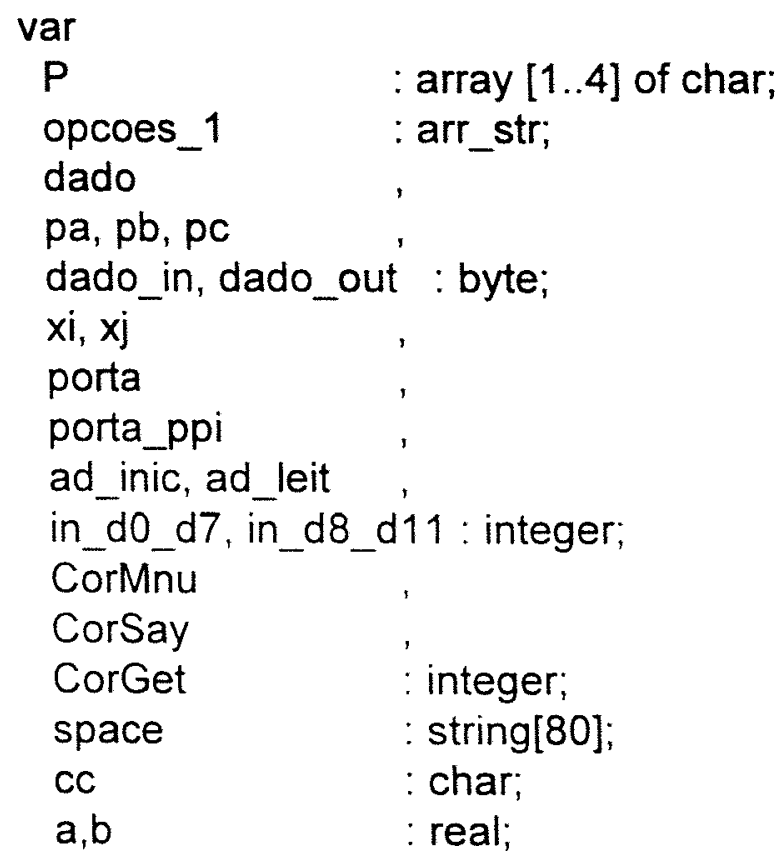

\{Função para conversao da leitura do conversor em volts \}

Function Ad_Volts(leit_ad : real) : real;

var

Volts : real;

begin

Volts : $=(9.940 / 4095.0) *$ leit_ad;

Ad_Volts : $=$ Volts;

end;

\{Função para Leitura de Porta

Function Input(porta:integer):byte; begin inline $(\$ 52 /$

$\$ 8 B / \$ 46 / \$ 041$

$\$ 89 / \$ C 21$

\$EC/

\$30/\$E4/

$\{$ PUSH DX
$\{$ MOV AX,[BP+04] $\}$
$\{$ MOV DX,AX
$\left\{\begin{array}{l}\text { IN AL,DX } \\ \text { XOR AH,AH }\end{array}\right\}$




$\begin{array}{llll}\$ 88 / \$ 46 / \$ 06 / & \{\text { MOV } & {[B P+06], A L} & \} \\ \$ 5 A) ; & \{P O P & D X & \}\end{array}$

\{Função para escrita em Porta \}

Procedure Output(porta : integer; dado : byte); begin inline $(\$ 52 /$ $\$ 8 \mathrm{~B} / \$ 46 / \$ 06 /$ $\$ 89 / \$ C 21$ $\$ 8 A / \$ 46 / \$ 04 /$ \$EEI end;

$\begin{array}{lll}\{\text { PUSH } & D X & \} \\ \{M O V & A X,[B P+06] & \} \\ \{M O V & D X, A X & \} \\ \{M O V & A L,[B P+04] & \} \\ \{\text { OUT } & D X, A L & \} \\ \text { POP } & D X & \}\end{array}$

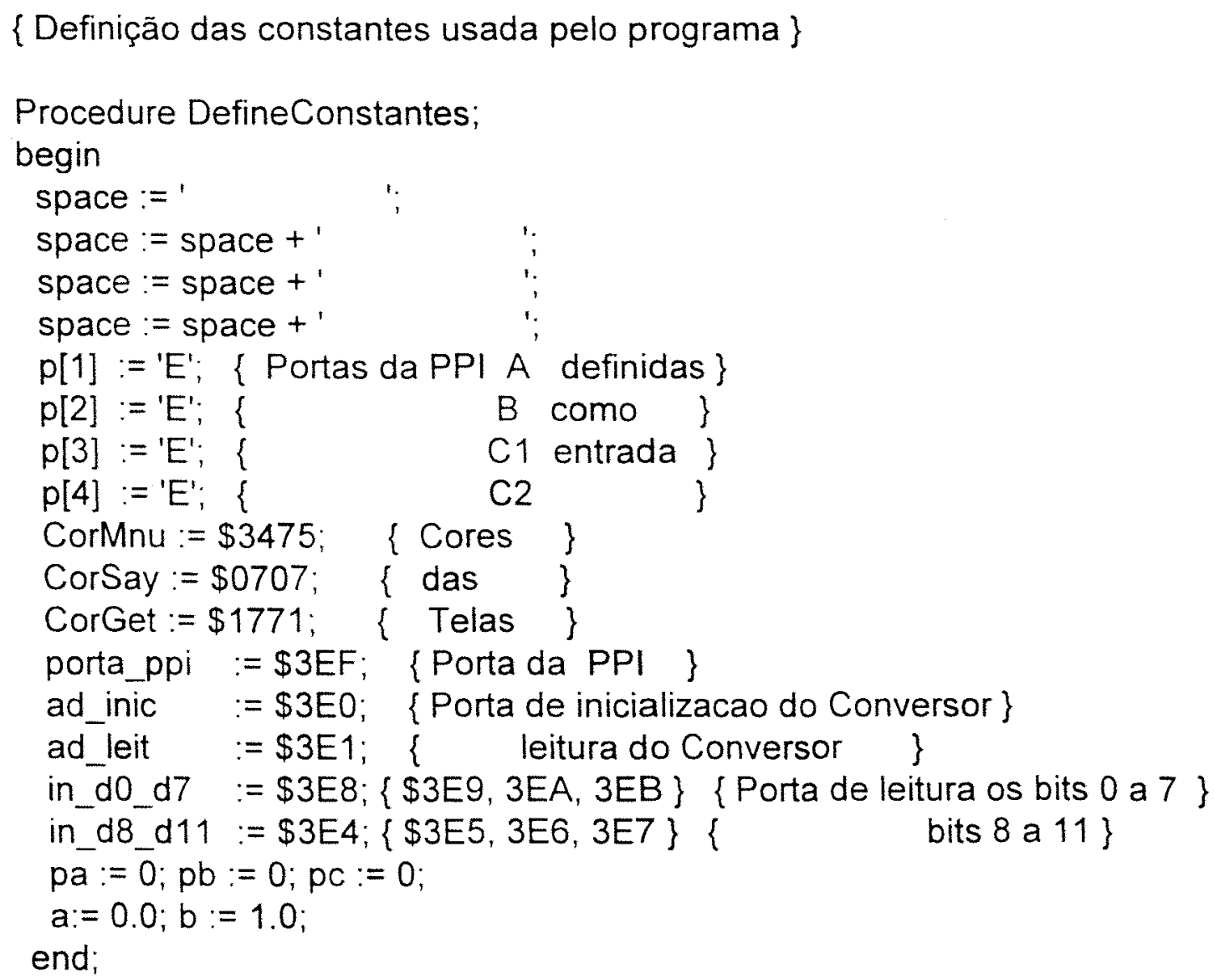


Function Media(n : integer; $x$ : arr_int) : real;

var

$\mathrm{i}, \mathrm{j}$ : integer;

xmedia, desvio : real;

$y$ : arr_int;

\{SUB\} Function subMedia(sn : integer; sx : arr_int): real;

var smedia : real ;

begin

smedia : $=0.0$

for $i:=1$ to sn do sMedia := smedia $+\mathbf{s x}[i] ;$

sMedia := sMedia / sn;

SubMedia := Smedia;

end;

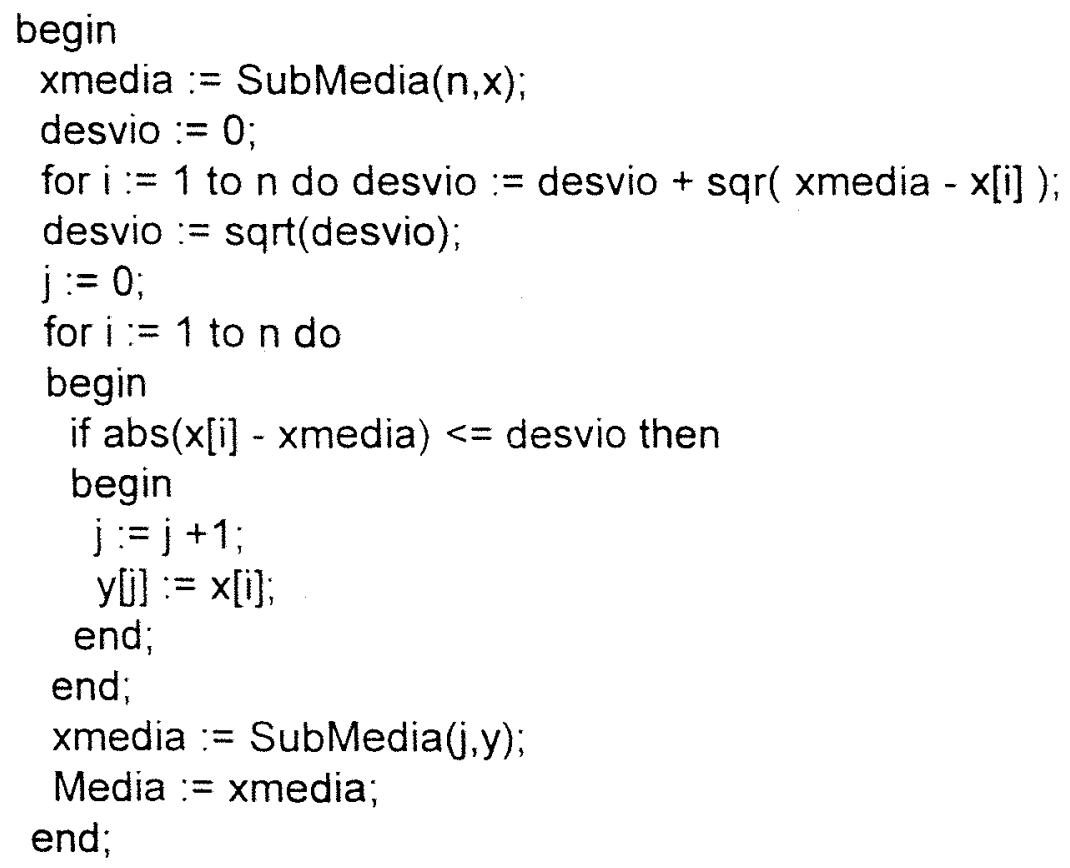

\{Função para leitura do Teclado para teclas de movimento de cursor \}

Function LeTeclado: char ;

var $\mathrm{c}$ : char;

begin

$\operatorname{Read}(\mathrm{Kbd}, \mathrm{C})$;

if ( $\mathrm{C}=\# 27$ ) and Keypressed then begin 


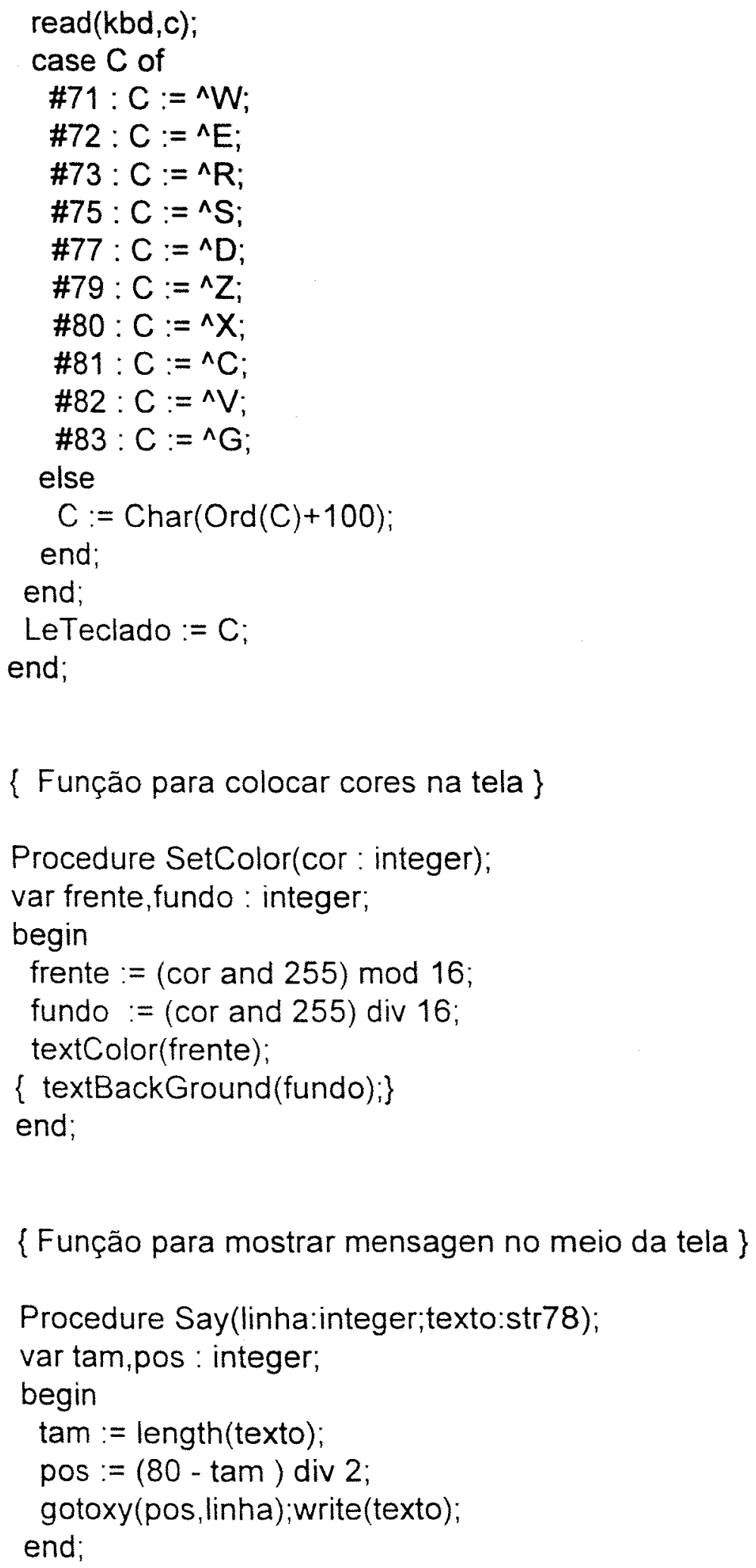


\{Função para mostrar e fazer a seleção de um ítem de menu \}

Function Menus(qtd:integer;opcoes:arr_str) : char;

var

$\mathrm{i}, \mathrm{j}$, tam,tmax : integer;

x_opcao,x_help : arr_str;

texto: string[78];

CC : char;

enter : boolean;

begin

setcolor( CorMnu div 256);

$\operatorname{tmax}:=1$

for $i:=1$ to qtd do

begin

tam :=1;

texto := opcoes[i];

for $j:=1$ to length(texto) do

begin

if texto[j] $=$ ',' then tam $:=j$;

if tam > tmax then tmax : $=$ tam;

end;

x_opcao[i] : $=\operatorname{copy}($ texto, $1, \operatorname{tam}-1)$;

$x \_$help $[i]:=\operatorname{copy}($ texto,tam +1 , length (texto) $-\operatorname{tam})$;

$x \_$help $[i]:=x$ help $[i]+$ space;

end;

$\operatorname{tmax}:=\operatorname{tmax}-1$;

for $i:=1$ to qtd do

begin

x_opcao[i] : $=\operatorname{copy}\left(x_{\text {o opcao }}[i]+\right.$ space $\left., 1, \operatorname{tmax}\right)$;

gotoxy $(3,5+i)$; write (x_opcao[i]);

end;

$i:=1$;

enter := false;

repeat

setColor(CorMnu mod 256);

gotoxy $(3,5+i)$; write (x_opcao[i]);

gotoxy $(2,23)$; write(x_help [i]);

cc := LeTeclado;

SetColor(CorMnu div 256);

gotoxy $(3,5+i)$; write(x_opcao[i]);

case $\mathrm{Cc}$ of

${ }^{\wedge} E:$ if $i=1$ then $i:=$ atd else $i:=i-1$;

${ }^{\wedge} X:$ if $i=$ qtd then $i:=1$ else $i:=i+1$; 


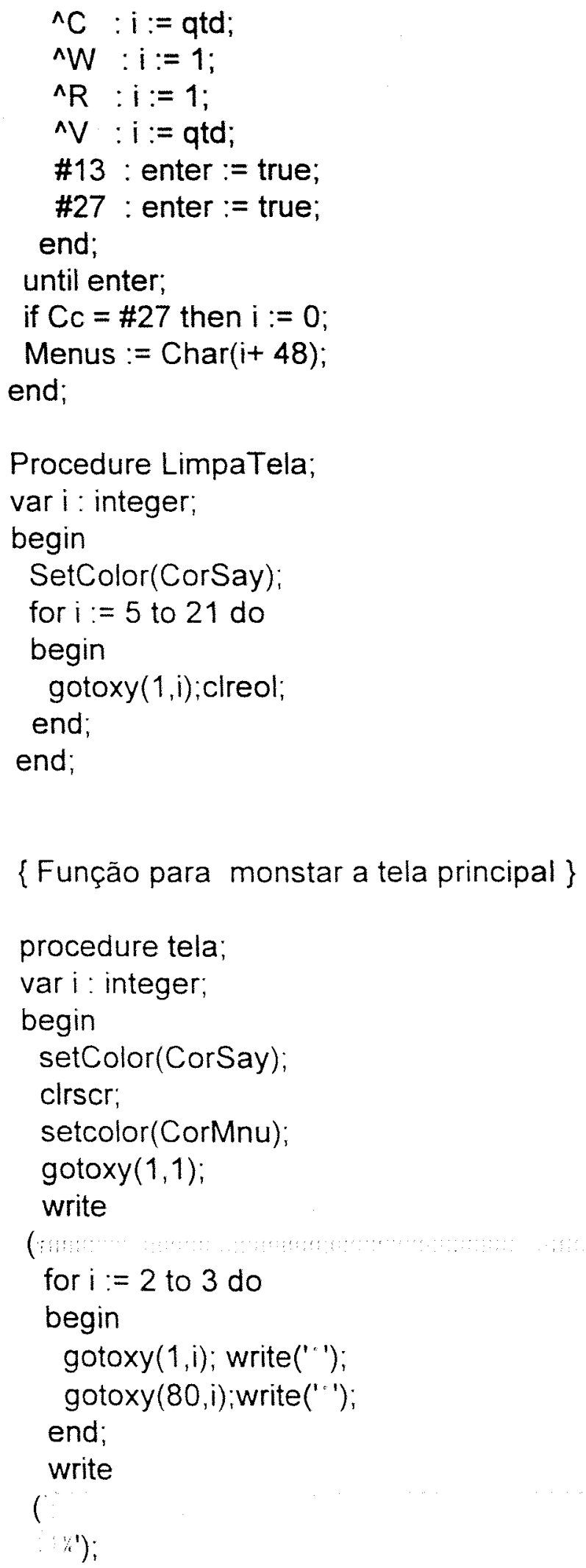




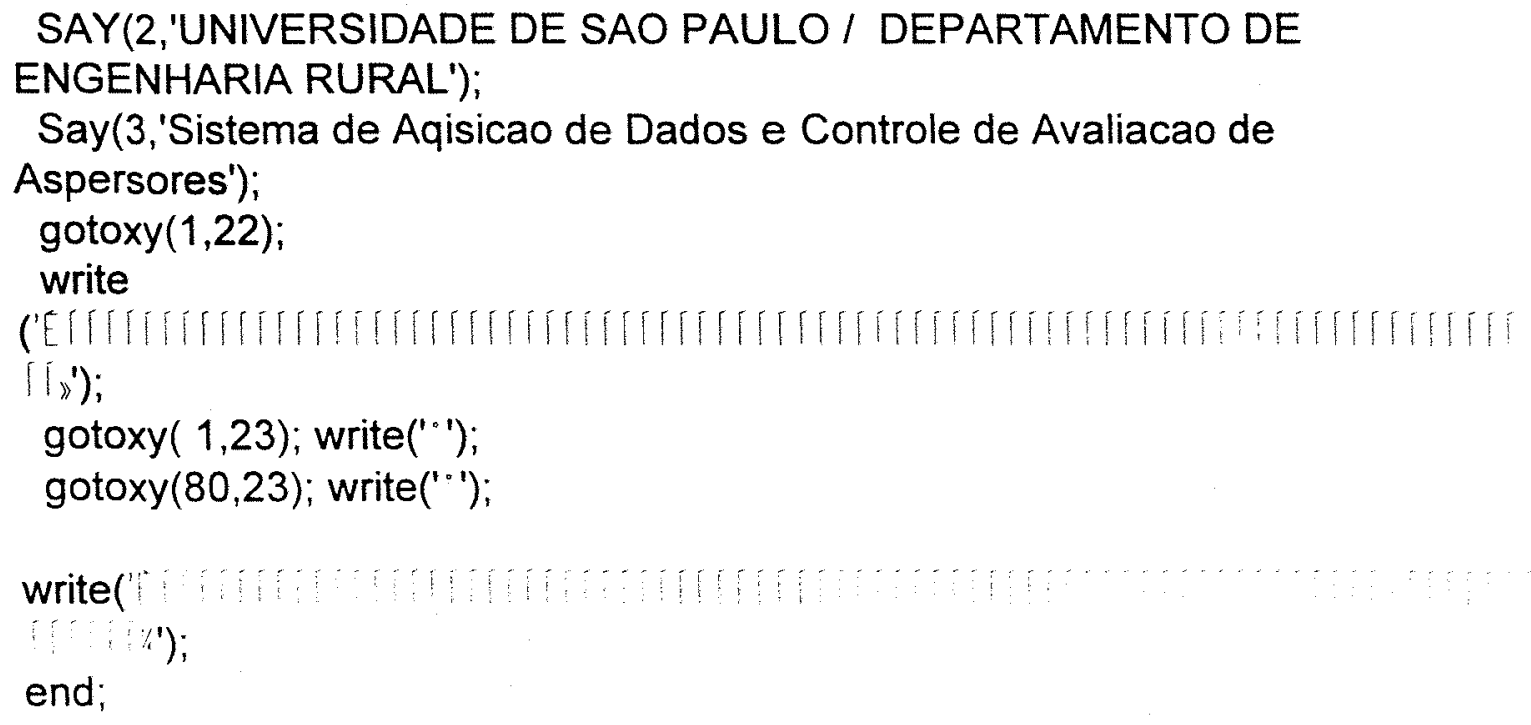

\{Função para transformar um número de um byte em hexadecimal e mostrá-lo na tela $\}$

Procedure Hexa(dado: byte);

var saida : string[2];

h: byte;

begin

$h:=$ dado shr 4;

if $h>9$ then $h:=h+7$;

$h:=h+48$;

saida $:=\operatorname{chr}(\mathrm{h})$;

$h:=$ dado and 15

if $h>9$ then $h:=h+7$;

$h:=h+48$;

saida : = saida $+\operatorname{chr}(\mathrm{h})$;

write(saida);

end;

\{Função para transformar um número inteiro em hexadecimal e mostrá-lo na tela \}

Procedure Hexa2(dado : integer);

var

meio_dado : byte;

begin

meio_dado := dado div 256;

Hexa(meio_dado); 


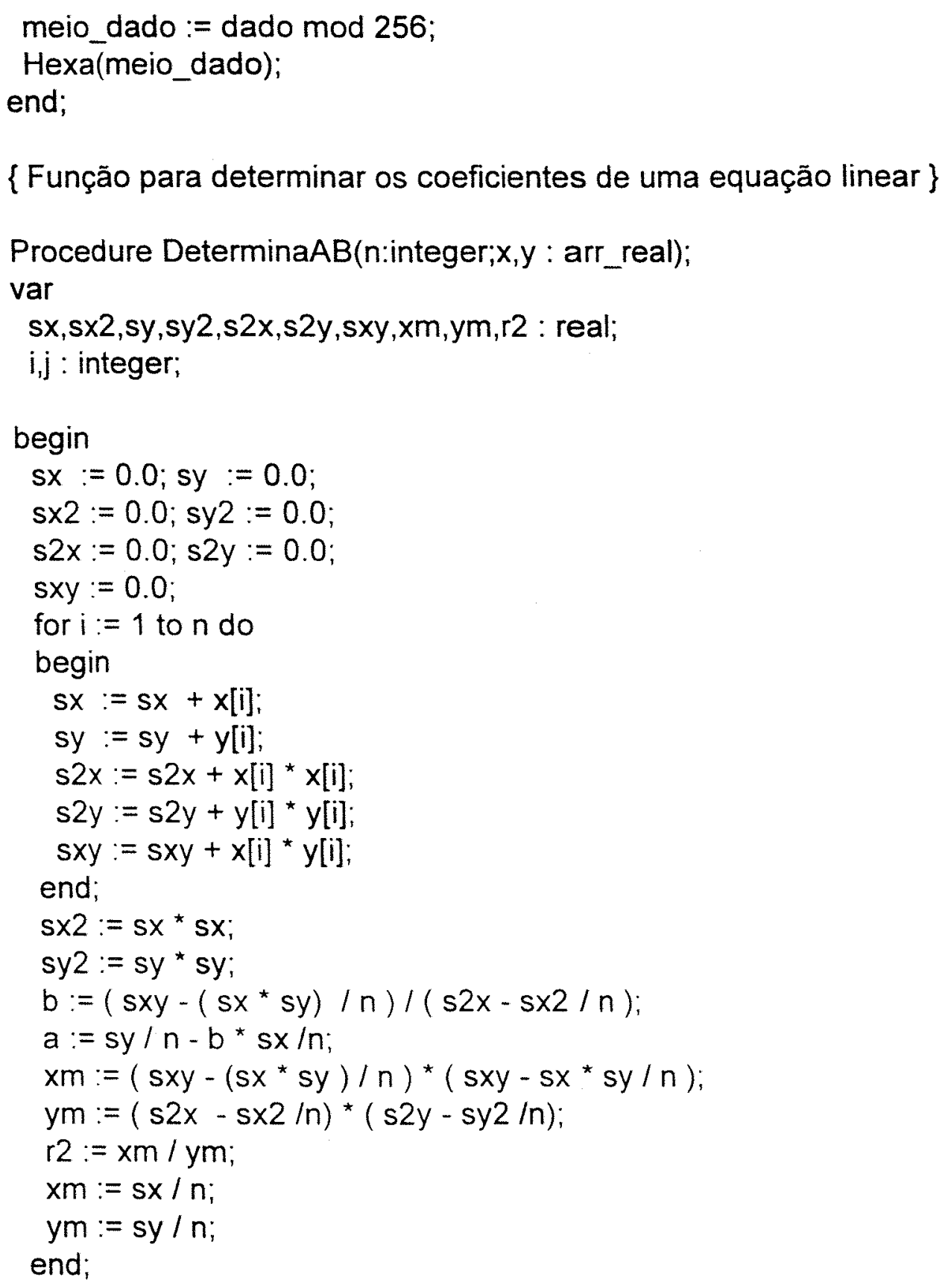

\{Função para definir os pinos da PPI se Entrada ou Saída

Procedure Programa_ppi;

var $i$ : integer;

opc : char;

begin

dado_out $:=\$ 80$; 


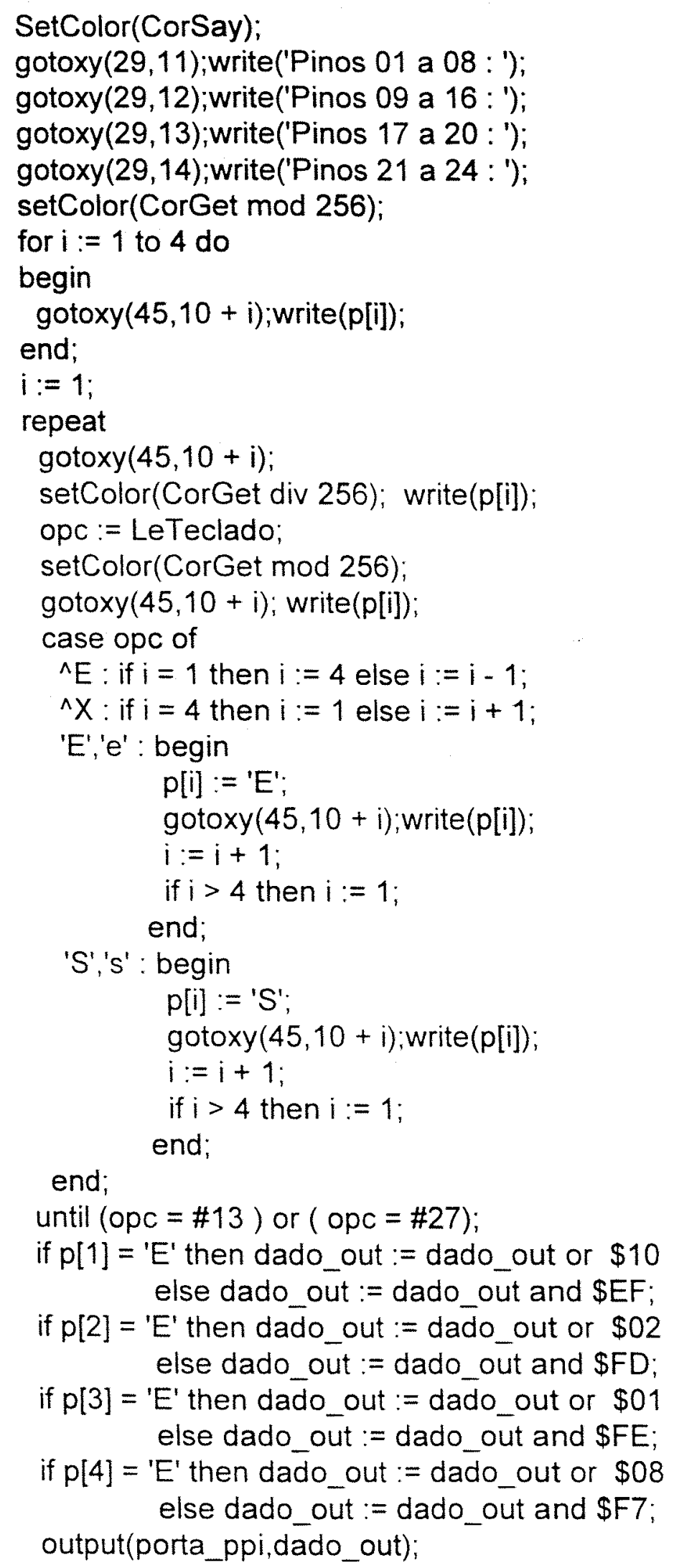




\section{LimpaTela;}

end;

\section{\{Função para leitura do Conversor A/D \}}

Function Le_AD: real;

var lido,loop,tenta, i integer;

ok : byte;

$x$ : arr int;

rlido : real;

begin

tenta $:=6$;

for $i:=1$ to tenta do

begin

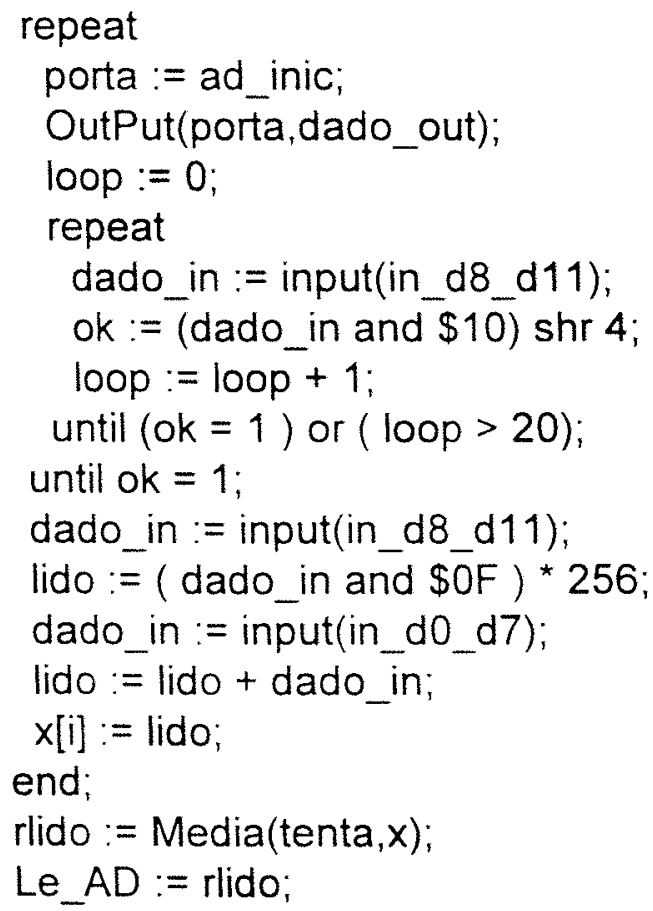

\{Função para ativar saídas da PPI \}

Procedure Saida_ppi(cporta:char; dado : byte);

begin

cporta := upcase (cporta);

porta := porta_ppi - 3;

if cporta $=$ ' $B$ ' then

porta : $=$ porta +1 ;

if cporta $=$ ' $\mathrm{C}$ ' then 


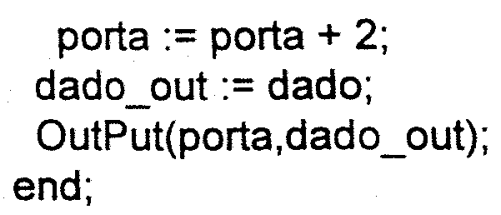




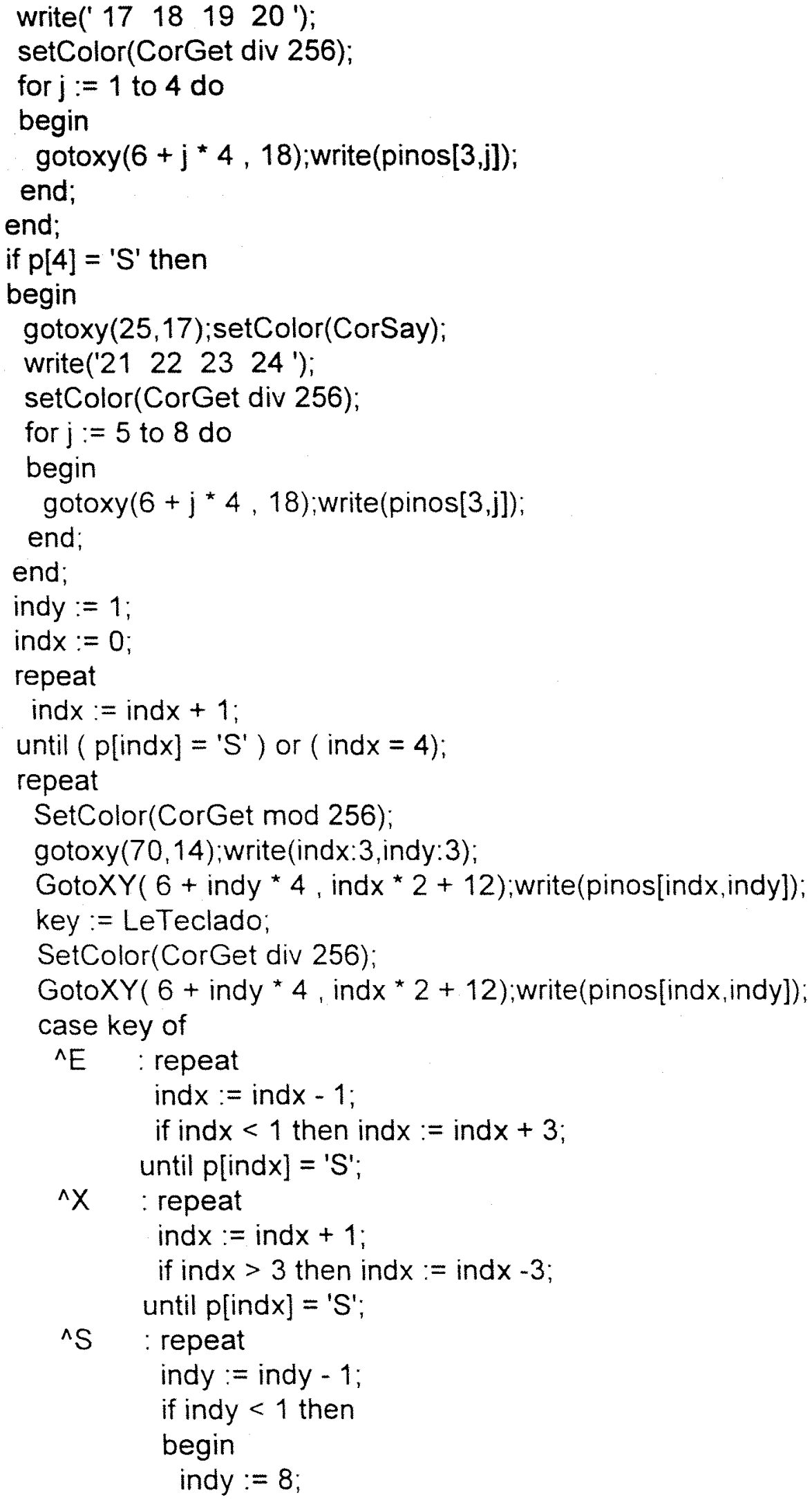




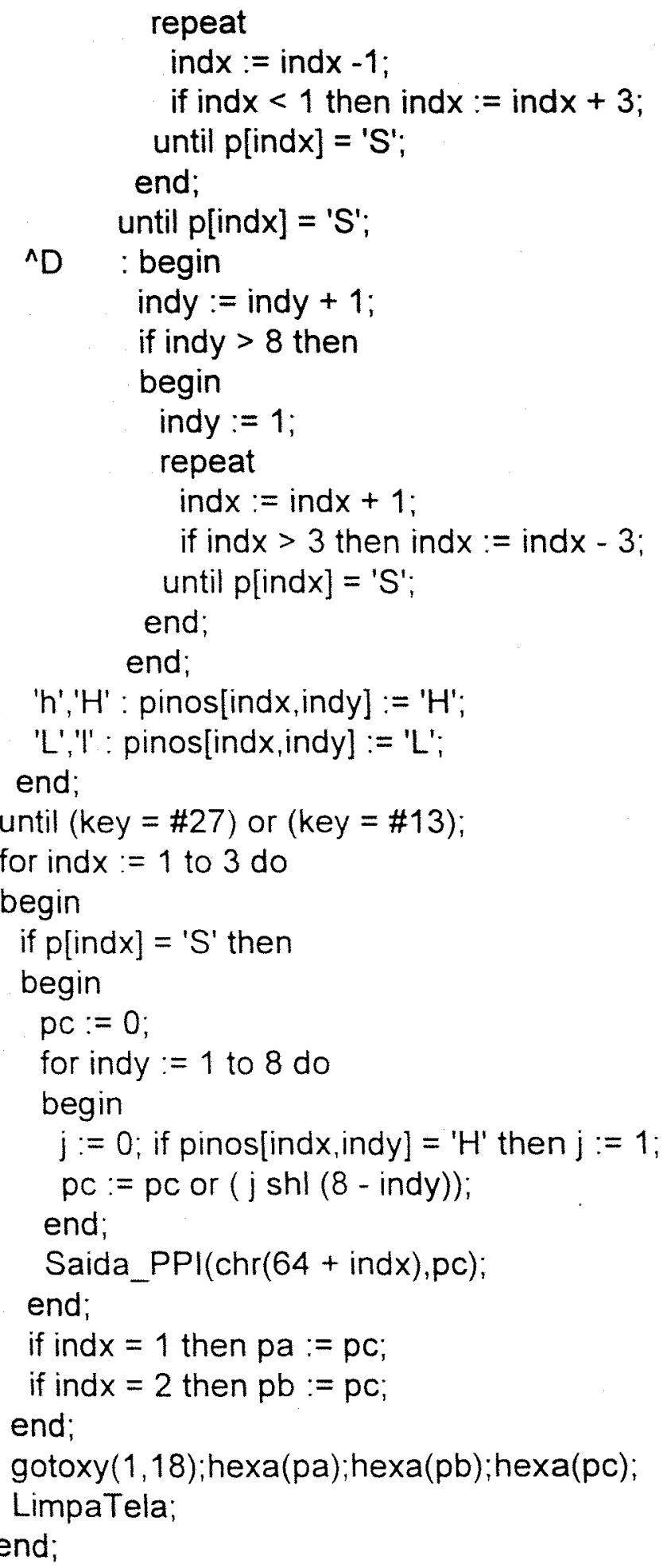

\{Função para leitura dos bits de Entrada da PPI \}

Procedure Le_PPI; 


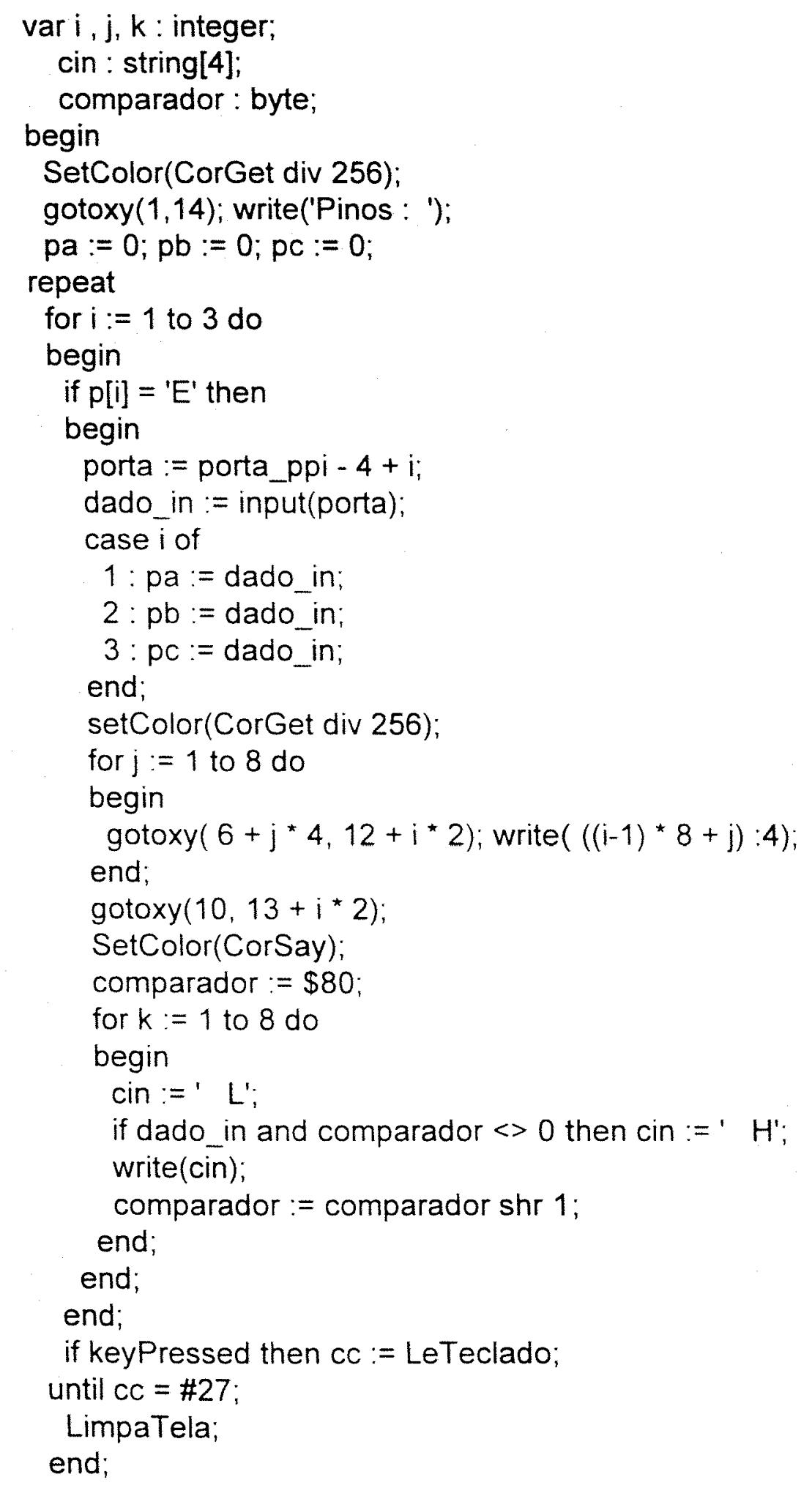

\{Função para efetuar a leitura do conversor e mostrar na tela 


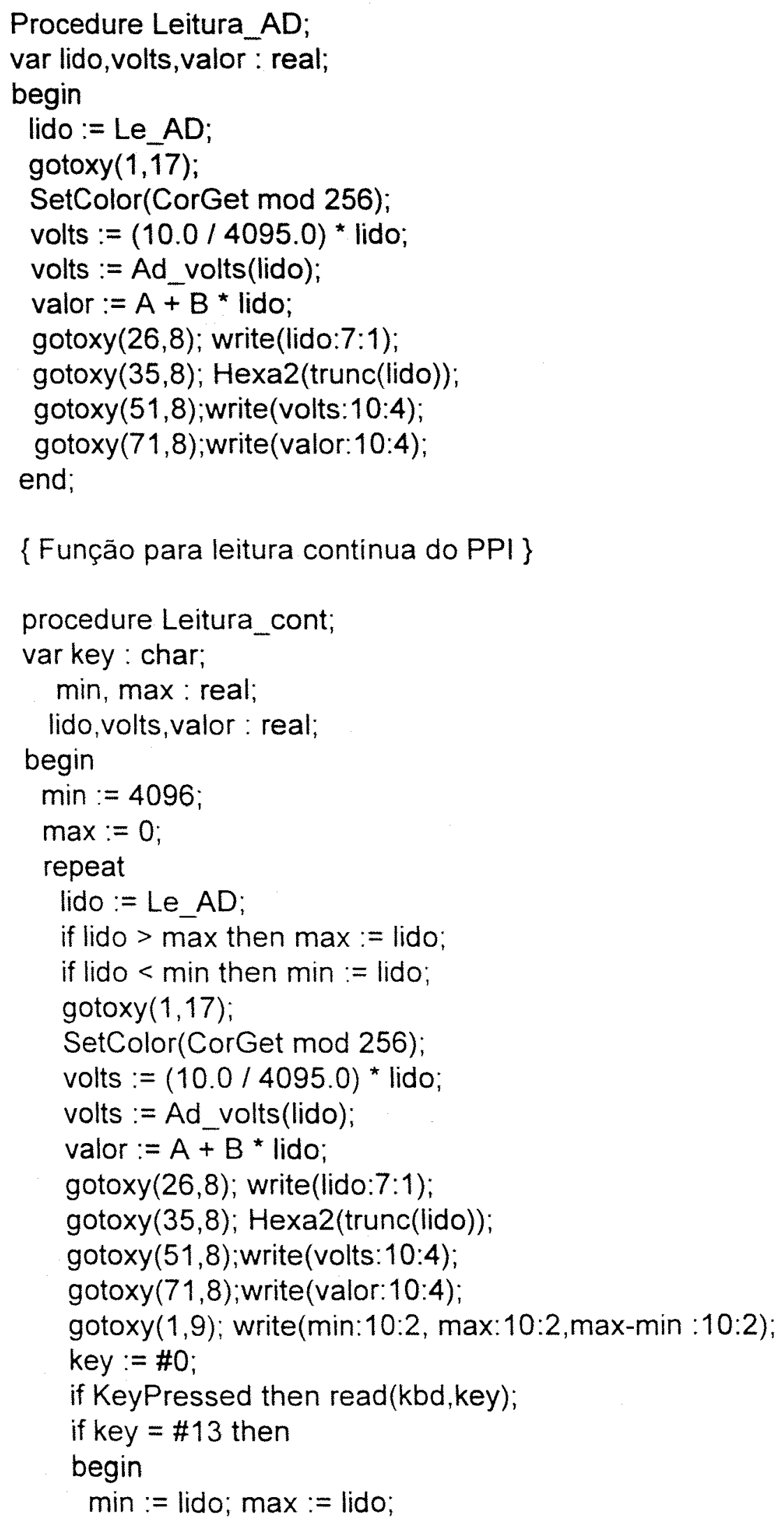


end;

$\{$ gotoxy $(20,11) ;$ write(ord(key)); $\}$

until Key = \#27;

LimpaTela;

end;

\{Função para leitura do conversor e gravação em arquivo texto \}

Procedure Gera_arq;

var arq_saida : text;

volts, valor,lido : real;

val : array[1..5] of real;

nome_arq : string[80];

indice,erro, atd, ii : integer;

key : char;

ok : boolean;

campos : ARR_str8;

begin

ok : = false;

val[1] $:=0.0 ;$ val[2] $:=0.0 ;$ val[3] $:=0.0 ;$ val[ $[4]:=0.0 ;$ val[5] $:=0.0$; repeat

setColor(CorGet mod 256);

gotoxy $(1,10)$; Write('Nome do arquivo: $\quad$ ');

setColor(CorGet div 256);

gotoxy $(19,10)$ :Read(nome_arq);

assign(arq_saida,nome_arq);

$\{\$ 1-\}$

reset(arq_saida);

erro := ioresult;

$\{\$ 1+\}$

if erro $=0$ then

begin

close(arq_saida);

SetColor(CorSay);

gotoxy $(1,21)$; Write('Arquivo ja existe. Apaga Anterior : (S/N)'); repeat

$\mathrm{cc}:=$ LeTeclado;

SetColor(CorSay);gotoxy (1,21); clreol;

$\mathrm{cc}:=$ upcase $(\mathrm{cc})$;

if $\mathrm{Cc}=$ ' $S$ ' then

ok:= true;

until $(C C=' S ')$ or $(C C=' N ')$;

end 


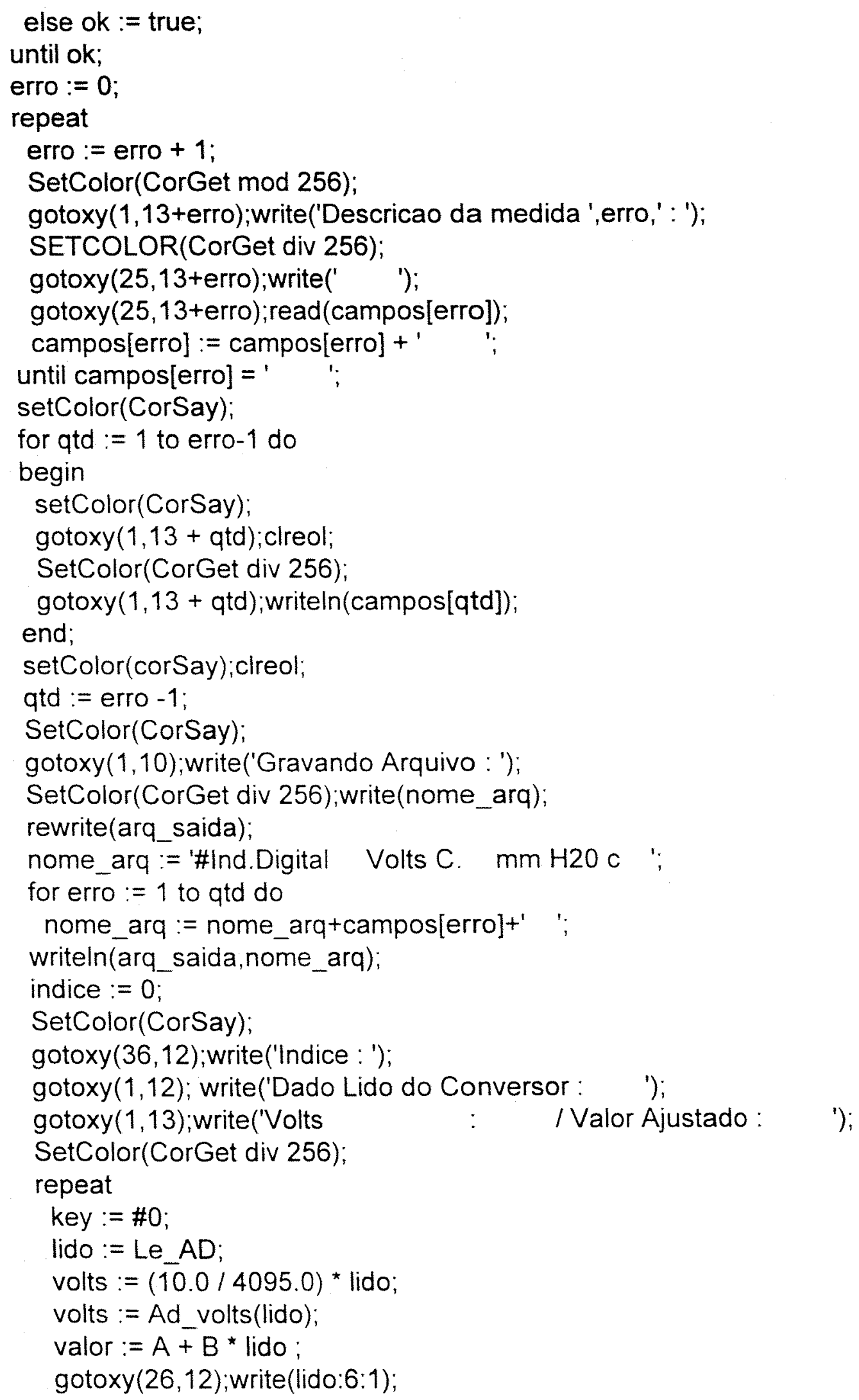




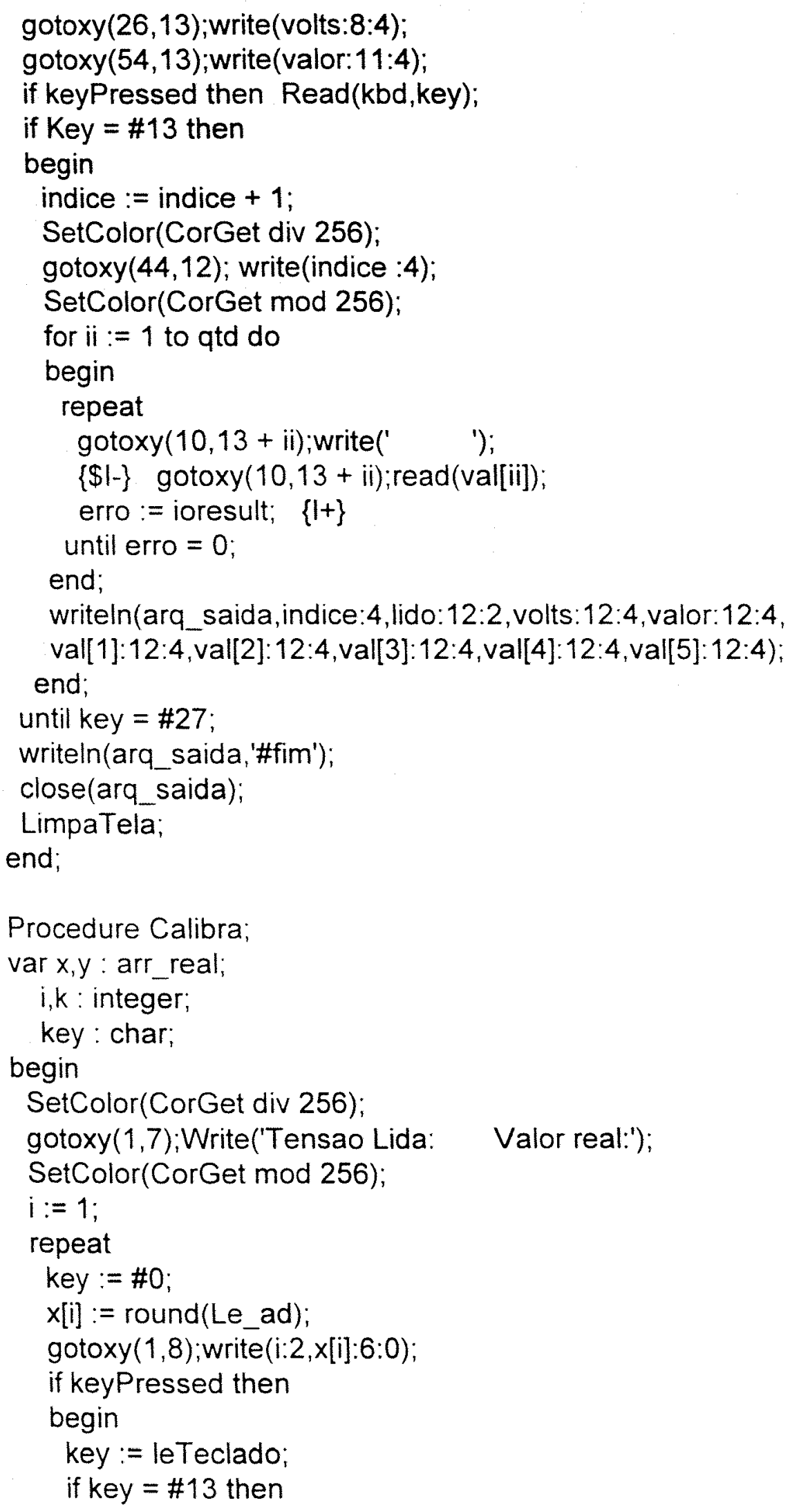




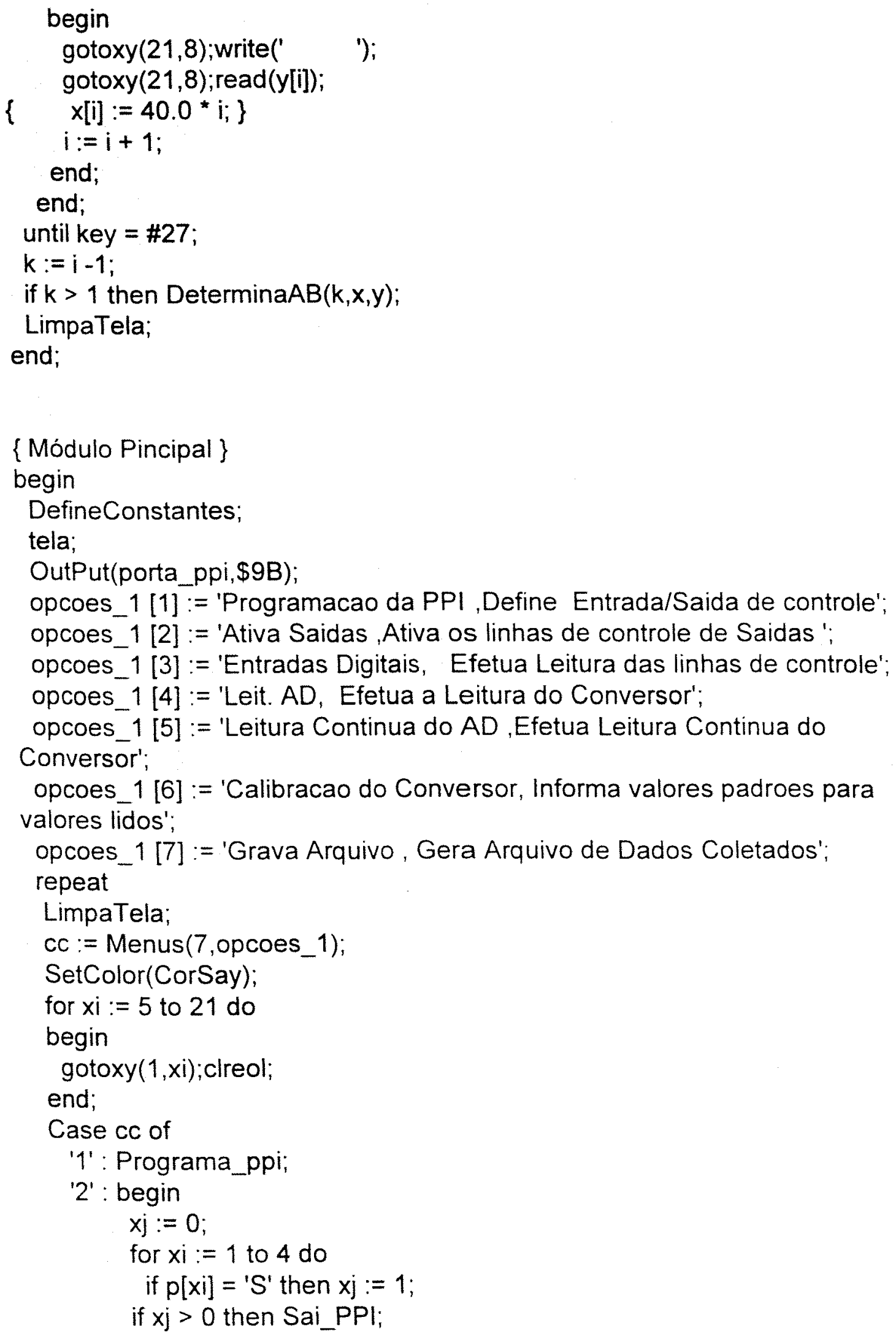




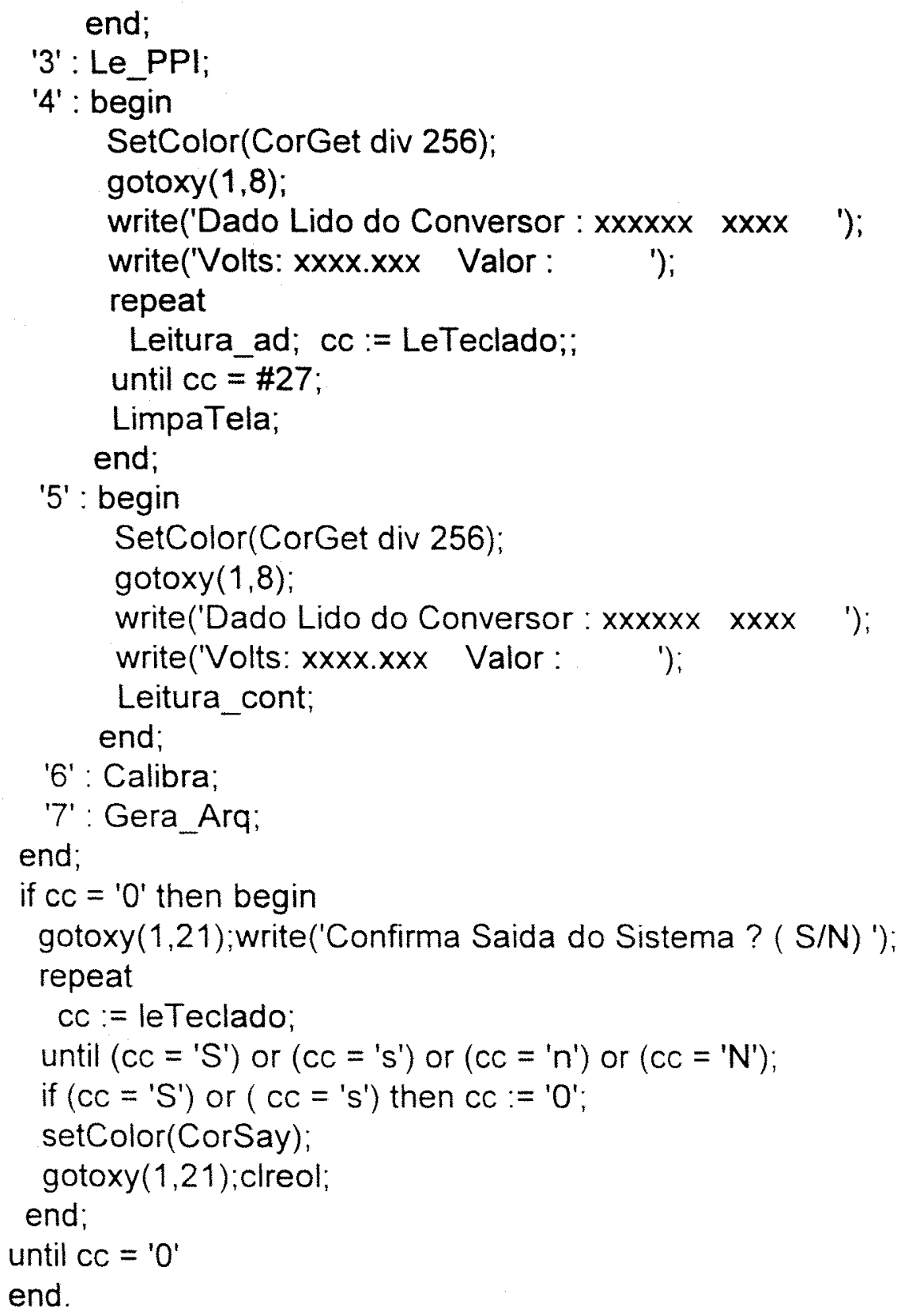




\section{CONSTRUÇĀO DO EQUIPAMENTO.}

Para a construção do equipamento, foi utilizado inicialmente um circuito integrado LM 2917, conversor de frequência em tensão, cujo resultado é dado pela equação:

$$
\begin{aligned}
& V_{\text {out }}=V_{\text {in }}{ }^{*} f_{\text {in }}{ }^{*} C{ }^{*} R \\
& \text { onde } \\
& V_{\text {out }}=\text { Tensão de Saida, } V_{;} \\
& V_{\text {in }}=\text { Tensão de alimentação, } V ; \\
& f_{\text {in }}=\text { Frequência de entrada, } H z ; \\
& C=\text { Capacitância (conjunto Vidro-Mercúrio-Cobre), Farad; } \\
& R=\text { Resistor, Ohms. } \\
& O \text { circuito foi alimentado com a tensão de } 10 \text { Volts, a frequência }
\end{aligned}
$$
de $4 \mathrm{kHz}$ foi fornecida por um circuito integrado NE555, a capacitância era variável, de acordo com a variação da altura de mercúrio, e o Resistor fixo.

Devido ao baixo valor da capacitância formada pelo conjunto mercúrio, vidro e cobre, a resposta do integrado LM 2917 era linear em alguns ensaios, porém não tinha repetibillidade. Nos ensaios efetuados por THONY \& GEORGES (1979), a variação da coluna de mercúrio era em torno de $60 \mathrm{~cm}$, ao passo que neste sensor a variação não ultrapassava $6 \mathrm{~cm}$. Isso justifica a eficiência naquele ensaio e não em nossa experiência. Isso provocou o 
abandono da construção deste tipo de sensor, partindo-se para outro projeto de construção do sensor.

Permanecendo a idéia da construção de um sensor capacitivo, partiu-se para se efetuar a leitura através de uma ponte de Wheatstone, alimentada por uma corrente alternada de 24 Volts pico a pico, e frequência de $600 \mathrm{~Hz}$. Para se obter uma tensão de alimentação constante, foi construido um oscilador a partir das tensões de alimentação de todo o conjunto $(+12$ e 12 Volts), com tensão e frequência constantes.

Essa corrente alternada constante alimenta uma ponte de Wheatstone onde um dos braços da ponte é o capacitor variável de acordo com a altura da coluna de mercúrio, e os outros braços formados por capacitores de $56 \mathrm{pF}$, correspondentes ao menor valor de capacitância fornecido pelo conjunto mercúrio, vidro e cobre. A corrente fornecida pelo desbalanceamento da ponte foi amplificada em 20 vezes, através de um circuito integrado $L M 358 \mathrm{M}$, e depois retificada, alimentando outro integrado LM $358 \mathrm{M}$, onde novamente foi amplificada. Esse amplificador foi construido de forma a se ajustar os valores de zero e de fundo de escala, para que a saída atingisse o valor de saída de 10 Volts. Com esses ajustes, é possivel se efetuar quaisquer medições de variações de coluna d'água, ajustando-se o conversor para o valor minimo de 
coluna d'água para tensão de 0 Volts, e o valor máximo de coluna d'água para 10 Volts.

Pode-se também calibrar este sensor construindo-se coletores com funís de diâmetros diferentes, cuja relação entre esses diâmetros e as colunas de água e mercúrio é apresentada a seguir:

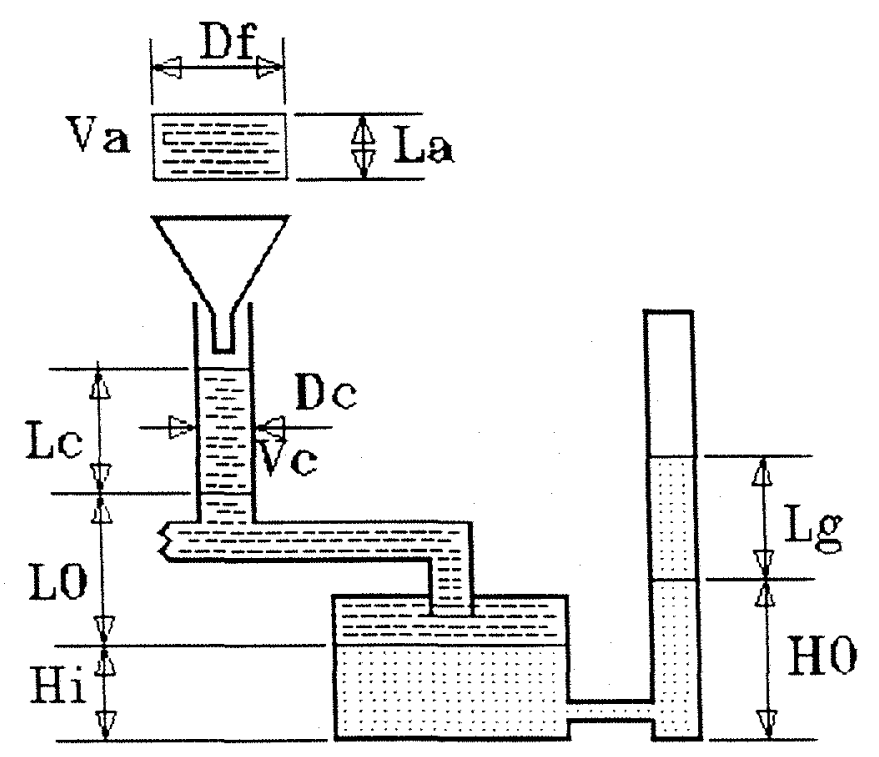

FIGURA 6 .Identificação dos elementos atuantes na pressão.

Considerando-se uma lâmina d'água de espessura $L_{a}$ aplicada no funil de diâmetro $D_{f}$, o volume $V_{a}$ da água coletada será : 


$$
V_{a}=\frac{L_{a} \cdot \pi \cdot D_{f}^{2}}{4}
$$

Este volume sendo depositado no coletor de diâmetro $D_{c}$,

proporcionará uma altura $L_{c}$ que vale:

$$
L_{c}=\frac{V_{a} \cdot 4}{\pi \cdot D_{c}^{2}}
$$

Sendo os volumes $V_{a}$ e $V_{c}$ iguais, substituindo o valor de $V_{c}$ da equação (1) em $V_{a}$ de (2), tem-se:

$$
L_{c}=L_{a} \cdot\left(\frac{D_{f}}{D_{c}}\right)^{2}
$$

Sendo as pressões nas superficies dos liquidos em ambos os lados iguais, pode-se afirmar que:

$$
\begin{aligned}
& \text { 13.6. } H_{i}+L_{0}+L_{c}=13,6 \cdot\left(H_{0}+L_{g}\right) \\
& \text { ou } \\
& L_{x}=\frac{L_{c}}{13,6}+\left(H_{i}-H_{0}+\frac{L_{0}}{13,6}\right)
\end{aligned}
$$


Sendo a segunda parte desta equação valores constantes em cada ensaio, e se pode fazer com que tenha o valor zero nos ajustes da tensão de sadia do sensor, essa expressão pode ser resumida em :

$$
L_{g}=\frac{L_{c}}{13,6}
$$

Substituindo o Valor de $L_{c}$ pelo valor obtido na equação (3) tem-

se:

$$
L_{x}=\frac{L_{a}}{13,6} \cdot\left(\frac{D_{f}^{2}}{D_{c}^{2}}\right)
$$

Sendo, devido a construção, a variação máxima permitida na coluna de Mercúrio $\left(L_{g}\right)$ de $60 \mathrm{~mm}$, esta equação serve para determinar a relação entre os diâmetros do funil e dos coletores, em função da lâmina de água máxima fornecida durante o ensaio. 


\section{ENSAIOS.}

Nos ensaios efetuados foram coletados os dados de altura de coluna d'água e tensão de saida do conversor, calibrando-se o aparelho com várias medidas de altura de coluna d'água, ajustando-se para cada ensaio os valores minimos e valores máximos de tensão. Estes valores foram ajustados entre 0 e 10 Volts. Os valores obtidos são os seguintes:

5.1 - Intervalo da coluna de água entre 361 e $760 \mathrm{~mm}$.

Neste intervalo de coluna de água, o sistema foi ajustado para tensões entre 0 e 9 Volts, obtendo-se os seguintes resultados: 
Tabela 1 - Intervalo da coluna de água entre 361 e $760 \mathrm{~mm}$.

\begin{tabular}{|c|c|c|c|c|}
\hline $\begin{array}{l}\text { Coluna de } \\
\text { água }(\mathrm{mm})\end{array}$ & $\begin{array}{l}\text { Tensão } \\
\text { gerada } \\
\text { (Volts) }\end{array}$ & $\begin{array}{l}\text { Coluna de água } \\
\text { Calculada }(\mathrm{mm})\end{array}$ & $\begin{array}{c}\text { Erro } \\
\text { Absoluto }\end{array}$ & $\begin{array}{c}\text { Erro } \\
\text { Percentual }\end{array}$ \\
\hline 760 & 9.00 & 759.766 & 0.234 & 0.059 \\
\hline 718 & 8.03 & 716.810 & 1.190 & 0.298 \\
\hline 712 & 7.95 & 713.267 & -1.267 & 0.317 \\
\hline 643 & 6.33 & 641.525 & 1.475 & 0.370 \\
\hline 628 & 6.02 & 627.797 & 0.203 & 0.051 \\
\hline 619 & 5.86 & 620.712 & -1.712 & 0.429 \\
\hline 614 & 5.68 & 612.740 & 1.260 & 0.316 \\
\hline 596 & 5.33 & 597.241 & -1.241 & 0.311 \\
\hline 589 & 5.14 & 588.827 & 0.173 & 0.043 \\
\hline 570 & 4.70 & 569.341 & 0.659 & 0.165 \\
\hline 565 & 4.65 & 567.127 & -2.127 & 0.533 \\
\hline 552 & 4.34 & 553.399 & -1.399 & 0.351 \\
\hline 537 & 3.96 & 536.571 & 0.429 & 0.108 \\
\hline 527 & 3.73 & 526.385 & 0.615 & 0.154 \\
\hline 520 & 3.58 & 519.742 & 0.258 & 0.065 \\
\hline 509 & 3.32 & 508.228 & 0.772 & 0.193 \\
\hline 500 & 3.13 & 499.814 & 0.186 & 0.047 \\
\hline 495 & 3.00 & 494.057 & 0.943 & 0.236 \\
\hline 491 & 2.96 & 492.286 & -1.286 & 0.322 \\
\hline 476 & 2.55 & 474.129 & 1.871 & 0.469 \\
\hline 470 & 2.43 & 468.815 & 1.185 & 0.297 \\
\hline 461 & 2.23 & 459.958 & 1.042 & 0.261 \\
\hline 450 & 2.06 & 452.429 & -2.429 & 0.609 \\
\hline 432 & 1.64 & 433.830 & -1.830 & 0.459 \\
\hline 420 & 1.31 & 419.216 & 0.784 & 0.197 \\
\hline 411 & 1.16 & 412.573 & -1.573 & 0.394 \\
\hline 409 & 1.07 & 408.588 & 0.412 & 0.103 \\
\hline 407 & 1.00 & 405.488 & 1.512 & 0.379 \\
\hline 399 & 0.89 & 400.616 & -1.616 & 0.405 \\
\hline 390 & 0.62 & 388.659 & 1.341 & 0.336 \\
\hline 380 & 0.45 & 381.131 & -1.131 & 0.283 \\
\hline 370 & 0.17 & 368.731 & 1.269 & 0.318 \\
\hline 361 & 0.00 & 361.203 & -0.203 & 0.051 \\
\hline
\end{tabular}


Coeficiente da regressão: $\quad 0,99986$

Erro percentual médio : $\quad 0,271 \%$

5.2 - Intervalo da coluna de água entre 178 e $695 \mathrm{~mm}$.

Neste intervalo de coluna de água, o sistema foi ajustado para tensões entre 0 e 7 Volts, obtendo-se os seguintes resultados:

Tabela 2 - Intervalo da coluna de água entre 178 e $695 \mathrm{~mm}$.

\begin{tabular}{|c|c|c|c|c|}
\hline $\begin{array}{c}\text { Coluna de } \\
\text { água }(\mathrm{mm})\end{array}$ & $\begin{array}{c}\text { Tensão } \\
\text { gerada } \\
\text { Volts) }\end{array}$ & $\begin{array}{c}\text { Coluna de água } \\
\text { Calculada }(\mathrm{mm})\end{array}$ & $\begin{array}{c}\text { Erro } \\
\text { Absoluto }\end{array}$ & $\begin{array}{c}\text { Erro } \\
\text { Percentual }\end{array}$ \\
\hline 414 & 3.22 & 415.728 & -1.728 & 0.334 \\
\hline 382 & 2.74 & 380.300 & 1.700 & 0.329 \\
\hline 358 & 2.46 & 359.633 & -1.633 & 0.316 \\
\hline 323 & 1.93 & 320.514 & 2.486 & 0.481 \\
\hline 578 & 5.47 & 581.800 & -3.800 & 0.735 \\
\hline 695 & 7.01 & 695.467 & -0.467 & 0.090 \\
\hline 651 & 6.36 & 647.491 & 3.509 & 0.679 \\
\hline 608 & 5.86 & 610.586 & -2.586 & 0.500 \\
\hline 521 & 4.62 & 519.062 & 1.938 & 0.375 \\
\hline 465 & 3.86 & 462.967 & 2.033 & 0.393 \\
\hline 412 & 3.18 & 412.776 & -0.776 & 0.150 \\
\hline 371 & 2.60 & 369.966 & 1.034 & 0.200 \\
\hline 290 & 1.51 & 289.514 & 0.486 & 0.094 \\
\hline 258 & 1.08 & 257.775 & 0.225 & 0.043 \\
\hline 217 & 0.55 & 218.656 & -1.656 & 0.320 \\
\hline 178 & 0.00 & 178.061 & -0.061 & 0.012 \\
\hline 184 & 0.09 & 184.704 & -0.704 & 0.136 \\
\hline
\end{tabular}

Coeficiente da regressão: $\quad 0,99985$

Erro percentual médio: $\quad 0,305 \%$ 
5.3 - Intervalo da coluna de água entre 161 e $733 \mathrm{~mm}$.

Neste intervalo de coluna de água, o sistema foi ajustado para tensões entre 2 e 5 Volts, obtendo-se os seguintes resultados:

Tabela 3 - Intervalo da coluna de água entre 161 e $733 \mathrm{~mm}$.

\begin{tabular}{|c|c|c|c|c|}
\hline $\begin{array}{l}\text { Coluna de } \\
\text { água }(\mathrm{mm})\end{array}$ & $\begin{array}{l}\text { Tensão } \\
\text { gerada } \\
\text { (Volts) }\end{array}$ & $\begin{array}{c}\text { Coluna da } \\
\text { água Calculada } \\
(\mathrm{mm})\end{array}$ & $\begin{array}{c}\text { Erro } \\
\text { Absoluto }\end{array}$ & $\begin{array}{c}\text { Erro } \\
\text { Percentual }\end{array}$ \\
\hline 194 & 2.17 & 193.638 & 0.362 & 0.063 \\
\hline 281 & 2.64 & 283.447 & -2.447 & 0.428 \\
\hline 267 & 2.57 & 270.071 & -3.071 & 0.537 \\
\hline 235 & 2.38 & 233.765 & 1.235 & 0.216 \\
\hline 639 & 4.51 & 640.772 & -1.772 & 0.310 \\
\hline 733 & 5.00 & 734.403 & -1.403 & 0.245 \\
\hline 702 & 4.83 & 701.918 & 0.082 & 0.014 \\
\hline 709 & 4.85 & 705.740 & 3.260 & 0.570 \\
\hline 192 & 2.17 & 193.638 & -1.638 & 0.286 \\
\hline 301 & 2.73 & 300.644 & 0.356 & 0.062 \\
\hline 414 & 3.32 & 413.383 & 0.617 & 0.108 \\
\hline 386 & 3.19 & 388.542 & -2.542 & 0.444 \\
\hline 358 & 3.02 & 356.058 & 1.942 & 0.339 \\
\hline 347 & 3.00 & 352.236 & -5.236 & 0.915 \\
\hline 161 & 1.97 & 155.421 & 5.579 & 0.975 \\
\hline 312 & 2.77 & 308.287 & 3.713 & 0.649 \\
\hline 580 & 4.21 & 583.447 & -3.447 & 0.603 \\
\hline 699 & 4.80 & 696.186 & 2.814 & 0.492 \\
\hline 651 & 4.53 & 644.594 & 6.406 & 1.120 \\
\hline 604 & 4.30 & 600.644 & 3.356 & 0.587 \\
\hline 521 & 3.91 & 526.122 & -5.122 & 0.895 \\
\hline 456 & 3.56 & 459.243 & -3.243 & 0.567 \\
\hline 412 & 3.34 & 417.205 & -5.205 & 0.910 \\
\hline 285 & 2.62 & 279.625 & 5.375 & 0.940 \\
\hline 258 & 2.50 & 256.695 & 1.305 & 0.228 \\
\hline 211 & 2.24 & 207.013 & 3.987 & 0.697 \\
\hline 173 & 2.07 & 174.529 & -1.529 & 0.267 \\
\hline 188 & 2.15 & 189.816 & -1.816 & 0.317 \\
\hline
\end{tabular}


Coeficiente da regressão: $\quad 0,99969$

Erro percentual médio : $\quad 0,474 \%$

5.4 - Intervalo da coluna de água entre 161 e $695 \mathrm{~mm}$.

Neste intervalo de coluna de água, o sistema foi ajustado para tensões entre 0 e 9 Volts, obtendo-se os seguintes resultados:

Tabela 4 - Intervalo da coluna de água entre 161 e $695 \mathrm{~mm}$.

\begin{tabular}{|c|c|c|c|c|}
\hline $\begin{array}{c}\text { Coluna de } \\
\text { água }(\mathrm{mm})\end{array}$ & $\begin{array}{c}\text { Tensão } \\
\text { gerada } \\
\text { Volts) }\end{array}$ & $\begin{array}{c}\text { Coluna da água } \\
\text { Calculada }(\mathrm{mm})\end{array}$ & $\begin{array}{c}\text { Erro } \\
\text { Absoluto }\end{array}$ & $\begin{array}{c}\text { Erro } \\
\text { Percentual }\end{array}$ \\
\hline 414 & 4.24 & 412.209 & 1.791 & 0.335 \\
\hline 382 & 3.76 & 383.749 & -1.749 & 0.327 \\
\hline 358 & 3.36 & 360.032 & -2.032 & 0.381 \\
\hline 347 & 3.12 & 345.802 & 1.198 & 0.224 \\
\hline 323 & 2.76 & 324.457 & -1.457 & 0.273 \\
\hline 161 & 0.00 & 160.812 & 0.188 & 0.035 \\
\hline 312 & 2.52 & 310.227 & 1.773 & 0.332 \\
\hline 578 & 7.06 & 579.411 & -1.411 & 0.264 \\
\hline 695 & 9.00 & 694.437 & 0.563 & 0.105 \\
\hline 651 & 8.28 & 651.747 & -0.747 & 0.140 \\
\hline 608 & 7.52 & 606.685 & 1.315 & 0.246 \\
\hline 521 & 6.05 & 519.526 & 1.474 & 0.276 \\
\hline 465 & 5.12 & 464.385 & 0.615 & 0.115 \\
\hline 412 & 4.26 & 413.394 & -1.394 & 0.261 \\
\hline 371 & 3.57 & 372.483 & -1.483 & 0.278 \\
\hline 290 & 2.17 & 289.475 & 0.525 & 0.098 \\
\hline 258 & 1.62 & 256.865 & 1.135 & 0.213 \\
\hline 215 & 0.94 & 216.546 & -1.546 & 0.290 \\
\hline 178 & 0.29 & 178.007 & -0.007 & 0.001 \\
\hline 184 & 0.37 & 182.750 & 1.250 & 0.234 \\
\hline
\end{tabular}

Coeficiente da regressão : 0,99993

Erro percentual médio : $\quad 0,221$ 
5.5 - Intervalo da coluna de água entre 190 e $712 \mathrm{~mm}$.

Neste intervalo de coluna de água, o sistema foi ajustado para tensões entre 1 e 8 Volts, obtendo-se os seguintes resultados:

Tabela 5 - Intervalo da coluna de água entre 190 e $712 \mathrm{~mm}$.

\begin{tabular}{|c|c|c|c|c|}
\hline $\begin{array}{l}\text { Coluna de } \\
\text { água }(\mathrm{mm})\end{array}$ & $\begin{array}{l}\text { Tensão } \\
\text { gerada } \\
\text { (Volts) }\end{array}$ & $\begin{array}{l}\text { Coluna da água } \\
\text { Calculada (mm) }\end{array}$ & $\begin{array}{c}\text { Erro } \\
\text { Absoluto }\end{array}$ & $\begin{array}{c}\text { Erro } \\
\text { Percentual }\end{array}$ \\
\hline 712 & 8.00 & 711.675 & 0.325 & 0.062 \\
\hline 700 & 7.82 & 698.287 & 1.713 & 0.328 \\
\hline 621 & 6.77 & 620.190 & 0.810 & 0.155 \\
\hline 656 & 7.22 & 653.660 & 2.340 & 0.448 \\
\hline 635 & 6.96 & 634.322 & 0.678 & 0.130 \\
\hline 622 & 6.79 & 621.678 & 0.322 & 0.062 \\
\hline 599 & 6.52 & 601.596 & -2.596 & 0.497 \\
\hline 589 & 6.38 & 591.183 & -2.183 & 0.418 \\
\hline 562 & 6.01 & 563.663 & -1.663 & 0.319 \\
\hline 549 & 5.83 & 550.275 & -1.275 & 0.244 \\
\hline 536 & 5.66 & 537.631 & -1.631 & 0.312 \\
\hline 517 & 5.36 & 515.318 & 1.682 & 0.322 \\
\hline 497 & 5.08 & 494.492 & 2.508 & 0.480 \\
\hline 471 & 4.79 & 472.923 & -1.923 & 0.368 \\
\hline 458 & 4.61 & 459.535 & -1.535 & 0.294 \\
\hline 428 & 4.16 & 426.065 & 1.935 & 0.371 \\
\hline 405 & 3.85 & 403.008 & 1.992 & 0.382 \\
\hline 373 & 3.48 & 375.488 & -2.488 & 0.477 \\
\hline 364 & 3.35 & 365.819 & -1.819 & 0.348 \\
\hline 347 & 3.11 & 347.968 & -0.968 & 0.185 \\
\hline 329 & 2.83 & 327.142 & 1.858 & 0.356 \\
\hline 301 & 2.49 & 301.854 & -0.854 & 0.164 \\
\hline 282 & 2.20 & 280.284 & 1.716 & 0.329 \\
\hline 270 & 2.04 & 268.384 & 1.616 & 0.310 \\
\hline 248 & 1.78 & 249.046 & -1.046 & 0.200 \\
\hline 220 & 1.40 & 220.782 & -0.782 & 0.150 \\
\hline 203 & 1.13 & 200.700 & 2.300 & 0.441 \\
\hline 190 & 1.00 & 191.031 & -1.031 & 0.198 \\
\hline
\end{tabular}


Coeficiente da regressão: $\quad 0,99989$

Erro percentual médio : $\quad 0,298 \%$

5.6 - Intervalo da coluna de água entre 390 e $643 \mathrm{~mm}$.

Neste intervalo de coluna de água, o sistema foi ajustado para tensões entre 3 e 9 Volts, obtendo-se os seguintes resultados:

Tabela 6 - Intervalo da coluna de água entre 390 e $643 \mathrm{~mm}$.

\begin{tabular}{|c|c|c|c|c|}
\hline $\begin{array}{c}\text { Coluna de } \\
\text { água }(\mathrm{mm})\end{array}$ & $\begin{array}{c}\text { Tensão } \\
\text { gerada } \\
\text { (Volts) }\end{array}$ & $\begin{array}{c}\text { Coluna da água } \\
\text { Calculada }(\mathrm{mm})\end{array}$ & $\begin{array}{c}\text { Erro } \\
\text { Absoluto }\end{array}$ & $\begin{array}{c}\text { Erro } \\
\text { Percentual }\end{array}$ \\
\hline 643 & 9.00 & 642.759 & 0.241 & 0.095 \\
\hline 628 & 8.63 & 627.167 & 0.833 & 0.329 \\
\hline 619 & 8.41 & 617.896 & 1.104 & 0.436 \\
\hline 614 & 8.35 & 615.368 & -1.368 & 0.541 \\
\hline 596 & 7.85 & 594.297 & 1.703 & 0.673 \\
\hline 589 & 7.77 & 590.926 & -1.926 & 0.761 \\
\hline 580 & 7.55 & 581.655 & -1.655 & 0.654 \\
\hline 565 & 7.13 & 563.956 & 1.044 & 0.413 \\
\hline 552 & 6.82 & 550.893 & 1.107 & 0.438 \\
\hline 537 & 6.52 & 538.251 & -1.251 & 0.494 \\
\hline 527 & 6.27 & 527.715 & -0.715 & 0.283 \\
\hline 495 & 5.46 & 493.582 & 1.418 & 0.561 \\
\hline 492 & 5.43 & 492.317 & -0.317 & 0.125 \\
\hline 476 & 5.06 & 476.725 & -0.725 & 0.287 \\
\hline 471 & 4.94 & 471.669 & -0.669 & 0.264 \\
\hline 461 & 4.65 & 459.448 & 1.552 & 0.613 \\
\hline 433 & 4.04 & 433.742 & -0.742 & 0.293 \\
\hline 432 & 4.00 & 432.057 & -0.057 & 0.022 \\
\hline 420 & 3.68 & 418.572 & 1.428 & 0.565 \\
\hline 411 & 3.53 & 412.251 & -1.251 & 0.494 \\
\hline 409 & 3.43 & 408.036 & 0.964 & 0.381 \\
\hline 407 & 3.44 & 408.458 & -1.458 & 0.576 \\
\hline 399 & 3.20 & 398.344 & 0.656 & 0.259 \\
\hline 390 & 3.00 & 389.916 & 0.084 & 0.033 \\
\hline & & & & \\
\hline
\end{tabular}


Coeficiente da regressão: $\quad 0,99981$

Erro percentual médio : $\quad 0,400 \%$

5.7 - Intervalo da coluna de água entre 288 e $760 \mathrm{~mm}$.

Neste intervalo de coluna de água, o sistema foi ajustado para tensões entre 4 e 7 Volts, obtendo-se os seguintes resultados:

Tabela 7 - Intervalo da coluna de água entre 288 e $760 \mathrm{~mm}$.

\begin{tabular}{|c|c|c|c|c|}
\hline $\begin{array}{c}\text { Coluna de } \\
\text { água }(\mathrm{mm})\end{array}$ & $\begin{array}{c}\text { Tensão } \\
\text { gerada } \\
(\text { Volts) }\end{array}$ & $\begin{array}{c}\text { Coluna da água } \\
\text { Calculada }(\mathrm{mm})\end{array}$ & $\begin{array}{c}\text { Erro } \\
\text { Absoluto }\end{array}$ & $\begin{array}{c}\text { Erro } \\
\text { Percentual }\end{array}$ \\
\hline 288 & 4.02 & 289.828 & -1.828 & 0.387 \\
\hline 354 & 4.42 & 353.061 & 0.939 & 0.199 \\
\hline 431 & 4.92 & 432.102 & -1.102 & 0.234 \\
\hline 468 & 5.14 & 466.881 & 1.119 & 0.237 \\
\hline 502 & 5.34 & 498.497 & 3.503 & 0.742 \\
\hline 493 & 5.30 & 492.174 & 0.826 & 0.175 \\
\hline 555 & 5.70 & 555.407 & -0.407 & 0.086 \\
\hline 607 & 6.03 & 607.574 & -0.574 & 0.122 \\
\hline 670 & 6.46 & 675.550 & -5.550 & 1.176 \\
\hline 755 & 6.95 & 753.011 & 1.989 & 0.421 \\
\hline 762 & 7.00 & 760.915 & 1.085 & 0.230 \\
\hline & & & & \\
\hline
\end{tabular}

Coeficiente da regressão: $\quad 0,99976$

Erro percentual médio : $\quad 0,364 \%$ 
5.8 - Intervalo da coluna de água entre 202 e $602 \mathrm{~mm}$.

Neste intervalo de coluna de água, o sistema foi ajustado para tensões entre 2 e 8 Volts, obtendo-se os seguintes resultados:

Tabela 8 - Intervalo da coluna de água entre 202 e $602 \mathrm{~mm}$.

\begin{tabular}{|c|c|c|c|c|}
\hline $\begin{array}{c}\text { Coluna de } \\
\text { água }(\mathrm{mm})\end{array}$ & $\begin{array}{c}\text { Tensão } \\
\text { gerada } \\
\text { Volts) }\end{array}$ & $\begin{array}{c}\text { Coluna da água } \\
\text { Calculada (mm) }\end{array}$ & $\begin{array}{c}\text { Erro } \\
\text { Absoluto }\end{array}$ & $\begin{array}{c}\text { Erro } \\
\text { Percentual }\end{array}$ \\
\hline 575 & 7.60 & 574.431 & 0.569 & 0.142 \\
\hline 570 & 7.54 & 570.440 & -0.440 & 0.110 \\
\hline 453 & 5.79 & 454.040 & -1.040 & 0.260 \\
\hline 400 & 4.94 & 397.503 & 2.497 & 0.624 \\
\hline 348 & 4.18 & 346.952 & 1.048 & 0.262 \\
\hline 278 & 3.16 & 279.108 & -1.108 & 0.277 \\
\hline 233 & 2.44 & 231.217 & 1.783 & 0.446 \\
\hline 202 & 2.00 & 201.951 & 0.049 & 0.012 \\
\hline 269 & 3.03 & 270.461 & -1.461 & 0.365 \\
\hline 351 & 4.28 & 353.604 & -2.604 & 0.651 \\
\hline 447 & 5.65 & 444.728 & 2.272 & 0.568 \\
\hline 530 & 6.97 & 532.527 & -2.527 & 0.632 \\
\hline 602 & 8.00 & 601.037 & 0.963 & 0.241 \\
\hline
\end{tabular}

Coeficiente da regressão: $\quad 0,99985$

Erro percentual médio: $\quad 0,353 \%$ 


\section{6 - CONCLUSÃO.}

Baseado na metodologia apresentada e nos resultados obtidos dos ensaios pode-se concluir que:

- Existe uma relação linear entre a tensão em Volts e a altura da coluna de água sobre o sensor de pressão, onde a equação de ajuste apresentou correlação de 0,9999 .

- Para os valores das amplitudes de variação de altura d'água utilizados em coleta de precipitação de aspersores o sensor de pressão pode ser ajustado para sinais de saída de 0 a 10 Volts.

- O sensor de pressão desenvolvido pode ser empregado para medir e registrar precipitação de aspersores de irrigação.

- A automação dos ensaios de aspersores é perfeitamente viável com a metodologia apresentada. 


\section{REFERÊNCIAS BIBLIOGRÁFICAS.}

COELHO, R.D. Regulagens de aspersores e seus efeitos sobre a uniformidade de aplicação de água e produtividade das culturas. Piracicaba, 1990. 141p. ( Mestrado - Escola Superior de Agricultura "Luiz de Queiroz" / USP).

CHRISTIANSEN, J.E. The uniformity of application off water by sprinkler systems. Agricultural Engeneering; St. Joseph, 22(3) : 89-92, 1941.

DODI JUNIOR, C. Construção de um sistema coletor automático para Ensaio de microaspersores. In: Congresso Brasileiro de Engenharia Agrícola, 1., Piracicaba, 1990. Anais. Piracicaba, SBEA, 1990. v1, p. 628.

FISHER G.R. \& WALLENDER, W. W. Collector size and test duration effects on splinker water distribuition measurements. Transactions of the ASAE, St. Joseph, 31(2):538-42, 1988.

BALASTREIRE L. A, Desenvolvimento de sistema de aquisição de dados em microcomputador. Brasilia, MIC/STI, 1990. 73 p. 
NATIONAL SEMICONDUCTOR CORPORATION. Analog devices; dataacquisition data book 1982. Sta.Clara, 1982, v.1.

NATIONAL SEMICONDUCTOR CORPORATION. Linear databook 1988. Sta. Clara, 1988. v. 3.

SATTO, J. Avaliação do desempenho dos aspersores. São Carlos, 1978. 77p. (Mestrado - Escola de Engenharia de São Carlos / USP).

SEGINER, 1.; KANTS, D., NIR, D. ; BERNUTH, R. D. von. Indoor measurement of single-radius splinker patterns. Transactions of the ASAE, St. Joseph, 35(2): 523-33, 1992.

SOLOMON, K. Yeld related interpretations od irrigation uniformity and efficiency measures. Irrigation Science, Ann Arbor, 5: 161-72, 1984.

SPIESS M. Automated catchments for sprinkler testing. Internal report. Fresno, California State University / Center for Irrigation Technology, 1983.

THONY, J. L. \& VACHAUD, G., Automatic measurement of soil-water pressure using a capacitance manometer, Journal of Hydrology, Amsterdam, 46:189-96, 1980.

VICTORIA, F.R.B. Avaliação de aspersores com perspectiva de operação em baixa pressão, visando economia de energia e uso de energia 
gravitacional para acionamento. Piracicaba, 1992 .74p (Mestrado Escola Superior de Agricultura "Luiz de Queiróz" / USP). 